\title{
The Neurocircuitry of Fear, Stress, and Anxiety Disorders
}

\author{
Lisa M Shin ${ }^{\star, 1,2}$ and Israel Liberzon ${ }^{3,4}$ \\ ${ }^{1}$ Department of Psychology, Tufts University, Medford, MA, USA; ${ }^{2}$ Department of Psychiatry, Massachusetts General \\ Hospital/Harvard Medical School, Boston, MA, USA; ${ }^{3}$ Psychiatry Service, Ann Arbor Veterans Affairs Medical Center, \\ Ann Arbor, MI, USA; ${ }^{4}$ Department of Psychiatry, University of Michigan, Ann Arbor, MI, USA
}

\begin{abstract}
Anxiety disorders are a significant problem in the community, and recent neuroimaging research has focused on determining the brain circuits that underlie them. Research on the neurocircuitry of anxiety disorders has its roots in the study of fear circuits in animal models and the study of brain responses to emotional stimuli in healthy humans. We review this research, as well as neuroimaging studies of anxiety disorders. In general, these studies have reported relatively heightened amygdala activation in response to disorder-relevant stimuli in post-traumatic stress disorder, social phobia, and specific phobia. Activation in the insular cortex appears to be heightened in many of the anxiety disorders. Unlike other anxiety disorders, post-traumatic stress disorder is associated with diminished responsivity in the rostral anterior cingulate cortex and adjacent ventral medial prefrontal cortex. Additional research will be needed to (1) clarify the exact role of each component of the fear circuitry in the anxiety disorders, (2) determine whether functional abnormalities identified in the anxiety disorders represent acquired signs of the disorders or vulnerability factors that increase the risk of developing them, (3) link the findings of functional neuroimaging studies with those of neurochemistry studies, and (4) use functional neuroimaging to predict treatment response and assess treatment-related changes in brain function.

Neuropsychopharmacology Reviews (2010) 35, 169-191; doi: I0.1038/npp.2009.83; published online 22 July 2009
\end{abstract}

Keywords: amygdala; fMRI; PET; anterior cingulate; insula; hippocampus

\section{INTRODUCTION}

Anxiety disorders are marked by excessive fear (and avoidance), often in response to specific objects or situations and in the absence of true danger, and they are extremely common in the general population. According to a recent epidemiological study, the lifetime prevalence of any anxiety disorder is $28.8 \%$ (Kessler et al, 2005). Anxiety disorders are associated with impaired workplace performance and hefty economic costs (Greenberg et al, 1999), as well as an increased risk of cardiovascular morbidity and mortality (Albert et al, 2005; Kawachi et al, 1994; Smoller et al, 2007). Given that anxiety disorders are a significant problem in the community, recent neuroimaging research has focused on determining the brain circuits that underlie them to inform the use of existing treatments and guide the possible development of new treatments. In the future, neuroimaging studies of anxiety disorders may also prove

${ }^{*}$ Correspondence: Dr LM Shin, Department of Psychology, Tufts University, 490 Boston Avenue, Medford, MA 02155, USA,

Tel: +617 627 2251, Fax: +617627 3181, E-mail: lisa.shin@tufts.edu

Received 15 April 2009; revised 20 June 2009; accepted 21 June 2009 to be clinically helpful in the prediction of treatment response.

Given that excessive fear is a key component of anxiety disorders, it is not surprising that the search for the neurocircuitry of anxiety disorders has its roots in and has been closely intertwined with studies of fear circuits in animal models. A large volume of experimental work has examined the neurocircuitry associated with fear responses, mainly in rodents, using primarily fear conditioning, inhibitory avoidance, and fear-potentiated startle models. Key components of fear circuitry including the amygdala (and its subnuclei), nucleus accumbens (including bed nucleus of stria terminalis BNST), hippocampus, ventromedial hypothalamus, periaqueductal gray, a number of brain stem nuclei, thalamic nuclei, insular cortex, and some prefrontal regions (mainly infralimbic cortex) have been identified in these studies (for recent reviews see Davis, 2006; Maren, 2008; Quirk and Mueller, 2008). These regions have their respective roles in the various components of fear processing such as the perception of threat or of unconditioned stimuli, the pairing of an unconditioned stimulus and conditioned response (learning/conditioning), the execution of efferent components of fear response, and 
the modulation of fear responses through potentiation, contextual modulation, or extinction. Some key findings from animal literature, such as the central role of amygdaloid nuclei in the acquisition of fear conditioning and expression of fear responses, the involvement of the hippocampus in contextual processing, and the importance of the infralimbic cortex in extinction recall, have been replicated across different studies and laboratories. These basic components of fear circuitry are well preserved across species and likely support similar functions in humans. Animal work using in vivo electrophysiological recording, tracing and lesions/reversible inactivation techniques was indispensable in acquiring this knowledge. Some recent work had even suggested that there might be separate fear and anxiety systems orchestrated through the central nucleus of the amygdala and the BNST, respectively (Davis, 2006). These types of findings are particularly exciting as they might allow for a better focus on the neurocircuits involved in pathological anxiety.

On the other hand, other important issues, such as the exact neuroanatomical region that stores fear memory traces, or the exact role of a particular process (eg, the role of reconsolidation in fear memory, Nader and Hardt, 2009), or of a particular region (eg, the insular cortex) are intensely debated and actively studied. Nevertheless, the basic fear-related neurocircuitry identified in rodents is a useful place to start examining anxiety-related neurocircuitry in humans. It is important to note that the exact roles of many brain regions are yet to be firmly established and could differ across species. Even regions such as the amygdala, hippocampus, and nucleus accumbens might be involved in different, additional, or even unique tasks in humans (eg, the role of the hippocampus in explicit verbal memory in humans). Finally, there are major differences between human anxiety/anxiety disorders and fear conditioning models in animals. These differences include the frequent absence of clear unconditioned stimuli (US) in human anxiety disorders, and the central roles of avoidance and cognitive components (eg, anticipatory anxiety) in humans. These unique characteristics of anxiety disorders suggest potential involvement of other brain regions in addition to those identified in rodents, such as areas of prefrontal cortex that are more unique to humans. Thus, although animal studies are indispensable in understanding basic fear neurocircuitry, in vivo human studies are critical for understanding the neurocircuitry of anxiety disorders.

In this review, we will discuss three main topics: (1) fear neurocircuitry in healthy humans; (2) stress as a normal response to internal and external stimuli, and (3) anxiety disorders as defined in human psychopathology. The first of these topics will include a discussion of Pavlovian fear conditioning and extinction, pharmacologically induced fear and anxiety states, and the assessment of emotional stimuli in humans. In the third topic, we review the role of brain regions such as the amygdala, medial prefrontal cortex (including the rostral anterior cingulate cortex (rACC) and dorsal anterior cingulate cortex (dACC)), hippocampus, and insular cortex in anxiety disorders (Figure 1). Finally, we discuss some of the limitations of neuroimaging studies of anxiety disorders as well as the directions that we expect the field to take in the near future. (For an outline of this review see the Appendix.)

\section{FEAR NEUROCIRCUITRY IN HUMANS}

\section{Pavlovian Fear Conditioning and Extinction}

Fear conditioning. In its most basic form, Pavlovian fear conditioning involves repeatedly presenting a previously neutral conditioned stimulus (CS; eg, a tone) with an aversive unconditioned stimulus (US; eg, a shock). After repeated pairings, the CS alone comes to elicit a conditioned fear response (eg, increased freezing, fear-potentiated startle, or skin conductance responses). Pavlovian fear conditioning has been used as a testable and translational, though admittedly simplistic, model of the acquisition of fears that might be relevant to some anxiety disorders like phobias and possibly to some aspects of post-traumatic stress disorder (PTSD).

Studies of Pavlovian fear conditioning in non-humans have highlighted the importance of the amygdala in the acquisition of fear conditioning (LeDoux, 2000; LeDoux et al, 1990; Pare et al, 2004; Sananes and Davis, 1992). Similarly, functional neuroimaging studies in humans have reported amygdala activation during fear conditioning (Alvarez et al, 2008; Barrett and Armony, 2009; Buchel et al, 1998, 1999; Cheng et al, 2003, 2006; Gottfried and Dolan, 2004; Knight et al, 2004, 2005; LaBar et al, 1998; Milad et al, 2007b; Morris and Dolan, 2004; Pine et al, 2001; Tabbert et al, 2006), even when the CS is presented below perceptual thresholds (Critchley et al, 2002; Knight et al,
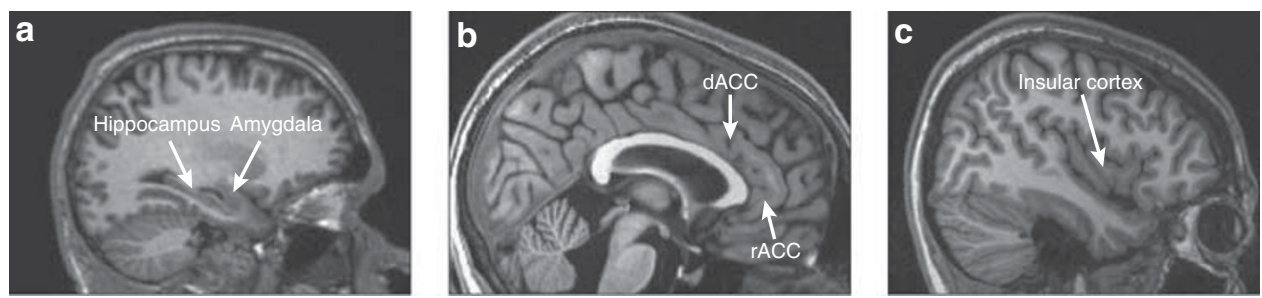

Figure 1. Magnetic resonance images (sagittal slices) showing the structures of interest in this review: (a) the hippocampus and the amygdala; (b) the dorsal anterior cingulate cortex (dACC) and the rostral anterior cingulate cortex (rACC); and (c) the insular cortex. 
2009; Morris et al, 2001) and even when more complex USs are used (Doronbekov et al, 2005; Klucken et al, 2009). In addition, amygdala activity has been associated with skin conductance changes during fear conditioning (Cheng et al, 2006; Furmark et al, 1997; LaBar et al, 1998; Phelps et al, 2001). Interestingly, amygdala activation in humans also has been observed in response to cues following (1) verbal instructions that discriminate between cues that predict shock $v s$ safety (even though no shock was actually administered) (Phelps et al, 2001), and (2) observational fear learning, whereby participants watch a video of another person experiencing a Pavlovian fear-conditioning paradigm (Olsson et al, 2007). What exactly amygdaloid activation represents in these latter paradigms is not entirely clear. It could suggest for example that: (1) higher order centers that decipher the anticipated predictive value of the cue, or that learn from observation using empathy, convey information to the amygdala, or (2) alternatively, that the human amygdala is less specific in its responses and is more sensitive to contextual modulation in the absence of a US. These interpretations could have potentially different implications for the understanding of the role of the amygdala in anxiety disorders.

Fear conditioning is also associated with increased activation in the dACC and rACC (Alvarez et al, 2008; Buchel et al, 1998, 1999; Dunsmoor et al, 2007; Klucken et al, 2009; LaBar et al, 1998; Marschner et al, 2008; Milad et al, 2007a, b; Morris and Dolan, 2004; Phelps et al, 2004). Activation in the dACC and rACC also occurs during observational fear learning (Olsson et al, 2007). In addition, dACC activation is positively correlated with differential skin conductance responses (Milad et al, 2007a). Fear conditioning studies (involving both specific CSs and contexts) also commonly report insular cortex activation (Alvarez et al, 2008; Buchel et al, 1999; Buchel et al, 1998; Critchley et al, 2002; Dunsmoor et al, 2007; Gottfried and Dolan, 2004; Klucken et al, 2009; Knight et al, 2009; Marschner et al, 2008; Morris and Dolan, 2004; Phelps et al, 2001, 2004) and hippocampal activation (Alvarez et al, 2008; Buchel et al, 1999; Knight et al, 2004, 2009; Lang et al, 2009; Marschner et al, 2008).

Extinction. Extinction learning occurs when a CS that previously predicted a US no longer does so, and over time, the conditioned response (eg, freezing or elevated skin conductance responses) decreases. Extinction learning or, more likely, the later recall of this learning involves the ventromedial prefrontal cortex (vmPFC) (Milad and Quirk, 2002; Morgan et al, 1993; Quirk et al, 2000, 2003, 2006) in rodents. Functional neuroimaging studies of healthy humans have reported vmPFC activation during extinction (Barrett and Armony, 2009; Gottfried and Dolan, 2004; Kalisch et al, 2006; Milad et al, 2007b) and the later recall of extinction (Milad et al, 2007b; Phelps et al, 2004). Skin conductance measures of extinction memory are positively correlated with vmPFC activation (Milad et al, 2007b; Phelps et al, 2004) and vmPFC cortical thickness (Milad et al, 2005). Activation of the amygdala and insular cortex also may occur during extinction learning or recall (Gottfried and Dolan, 2004; LaBar et al, 1998; Milad et al, 2007b; Phelps et al, 2004), and greater amygdala responses during extinction have been associated with higher trait anxiety (Barrett and Armony, 2009). Finally, extinction can be modulated by context (ie, the surroundings in which extinction takes place), and the hippocampus has a role in this process. In rodents, dorsal hippocampal lesions reduce the context-dependence of extinction (Bouton et al, 2006). In a recent fMRI study, hippocampal activation to the $\mathrm{CS}+$ occurred in the extinction context but not in the conditioning context (Kalisch et al, 2006). Hippocampal activation was also positively correlated with vmPFC activation in this study (Kalisch et al, 2006), suggesting that hippocampal-vmPFC interactions may be important for the contextual modulation of extinction.

\section{Fear States and Responses to Emotional Stimuli}

Pharmacological challenge. Another way to examine the mediating functional neuroanatomy of fear or anxiety is to use specific pharmacological agents to provoke such states in healthy individuals during PET or fMRI scanning. For example, cholecystokinin-4 (CCK-4) is associated with increases in subjective states of fear and anxiety, as well as increased activation in the amygdala, insular cortex, claustrum, cerebellum, brain stem, and the ACC (Benkelfat et al, 1995; Eser et al, 2009; Javanmard et al, 1999; Schunck et $a l, 2006)$. In addition, two studies reported dACC increases during anticipatory anxiety preceding the CCK administration (Eser et al, 2009; Javanmard et al, 1999). It is important to keep in mind, however, that CCK-B receptor agonists like pentagastrin also have direct effects on stress axis stimulation independent of their effects on subjective experience of distress/fear (Abelson et al, 2005, 2008). Procaine administration has been associated with elevated subjective ratings of fear/anxiety, activation of the amygdala, ACC, and insular cortex (Ketter et al, 1996; Servan-Schreiber et al, 1998), and deactivation of neocortical structures (Servan-Schreiber et al, 1998). Furthermore, amygdala activity was positively correlated with subjective reports of anxiety (Ketter et al, 1996; Servan-Schreiber et al, 1998). Interestingly, those subjects who did not have a panic attack in response to procaine had greater activation in the rACC compared with those who did have a panic attack (Servan-Schreiber et al, 1998), consistent with the idea that the rACC may perform a regulatory or inhibitory function (Mayberg, 1997). The alpha-2 adrenergic antagonist yohimbine has likewise been associated with increased normalized blood flow in medial prefrontal cortex, insular cortex, and cerebellum in healthy individuals (Cameron et al, 2000). A major caveat in the interpretation of pharmacological challenge studies, however, is the difficulty in disentangling the effects that are specific to fear induction from the direct effect of a pharmacological agent on regional brain activity and from the non-specific effects of the pharmacological agent.

Emotional stimuli. Over the past two decades, functional neuroimaging studies have shown that a core set of brain 
regions mediate responses to emotional stimuli in healthy humans. (For reviews, see Phan et al, 2002; Phan et al, 2004b). The relevance of these studies to fear/anxiety circuitry is two-fold: (1) A significant number of these emotional activation paradigms utilize stimuli that depict and/or elicit fear, and (2) these studies shed light on more general emotion-generating neurocircuitry. PET and fMRI studies have reported amygdala activation in response to emotionally negative photographs (Britton et al, 2006; Hariri et al, 2002; Irwin et al, 1996; Lane et al, 1997a; Paradiso et al, 1999; Phan et al, 2003b; Reiman et al, 1997; Taylor et al, 1998), odors (Zald and Pardo, 1997) and tastes (Zald et al, 1998). Several studies have reported amygdala activation to positive stimuli as well (Garavan et al, 2001; Hamann and Mao, 2002; Hamann et al, 1999, 2002; Liberzon et al, 2003), which suggests that the amygdala responds more broadly to emotionally arousing and/or salient stimuli (Phan et al, 2004b). Reappraisal of emotionally negative photographs is associated with reduced amygdala activation (Ochsner et al, 2002) and increased ventromedial prefrontal cortex activation (Urry et al, 2006). Finally, amygdala activation during encoding of emotionally arousing stimuli is correlated with the subsequent recollection of those stimuli (Cahill et al, 1996; Dolcos et al, 2004, 2005; Hamann et al, 1999).

Medial prefrontal cortex, including the rACC, also activates in response to emotional pictures (Lane et al, 1997a, b; Phan et al, 2003a, b, 2004a; Reiman et al, 1997) and may mediate self-referential processing (Kelley et al, 2002; Lane et al, 1997a; Zysset et al, 2002). Although the medial prefrontal cortex may activate regardless of task or valence, the rACC may be more likely to activate when a cognitive task is performed during scanning (Phan et al, 2002). Ventromedial PFC responses to fear-related images have been negatively associated with cortisol reactivity (Root et al, 2009). The dACC also activates in response to emotional photographs (Britton et al, 2006; Teasdale et al, 1999) and aversive tastes (Zald et al, 1998). Finally, the insular cortex is responsive to aversive stimuli (Phan et al, 2004a), internally generated sadness (Lane et al, 1997b; Reiman et al, 1997) and disgust-related stimuli (Britton et al, 2006).

Emotional facial expressions. Interestingly, the same neurocircuitry that has been implicated in fear/anxiety responses in humans is readily activated by stimuli that are not intrinsically threatening, but may convey information regarding the presence of threat in the environment or about the fearful emotional state of others. Responses in the amygdala are readily elicited by photographs of facial expressions, especially those of fear (Breiter et al, 1996a; Davis and Whalen, 2001; Fitzgerald et al, 2006; Morris et al, 1996; Vuilleumier and Pourtois, 2007; Whalen et al, 2001), even when presented below conscious awareness (Morris et al, 1998; Whalen et al, 1998, 2004). Emotional facial expressions have also been associated with activation in the dACC, rACC, medial frontal gyrus, and insular cortex (Fitzgerald et al, 2006; Gorno-Tempini et al, 2001; Morris et al, 1996; Phillips et al, 1997, 2004; Sabatini et al, 2009; Sprengelmeyer et al, 1998).
Brain responses to the relatively ambiguous facial expression of surprise have been shown, in some studies, to depend on the extent to which individual subjects interpreted these expressions as positive or negative; more negative interpretations were associated with greater amygdala and lower ventral medial prefrontal cortex activation (Kim et al, 2003). These findings are consistent with the notion that the amygdala and medial prefrontal cortex are reciprocally modulated (eg, Garcia et al, 1999). Furthermore, the experimental manipulation of the context in which surprise facial expressions are presented alters brain activation patterns in a similar way: surprise expressions associated with a negative context elicited more amygdala activation than those associated with a positive context (Kim et al, 2004). These amygdala activations were positively correlated with activation in the dACC (Kim et al, 2004).

Of relevance to our later discussion of anxiety disorders are findings that suggest that healthy individuals with high scores on anxiety measures have greater amygdala and insular cortex responses to emotional (angry, fearful, and happy) faces and less rACC activation than participants with normative scores on these measures (Bishop et al, 2004a, b; Stein et al, 2007). Similarly, trait anxiety has been positively correlated with amygdala responses to neutral faces (Somerville et al, 2004).

\section{Summary}

Studies of fear conditioning, pharmacologically induced fear, and responses to emotional stimuli and facial expressions have provided evidence that the human amygdala, although responsive to multiple salient stimuli, responds reliably and potentially preferably to stimuli that predict threat and can be involved in mediating fear/anxiety states. Given that patients with anxiety disorders experience fear and distress in response to possible predictors of threat, the amygdala has been hypothesized to be hyperresponsive in some anxiety disorders. In the next section, we will review the evidence related to this hypothesis.

Studies of extinction have highlighted the potential involvement of the vmPFC and hippocampus in the process of learning and remembering that stimuli that used to predict threat no longer do. One possible reason for exaggerated fear, anxiety, and distress in patients with anxiety disorders is that these emotional responses fail to extinguish or that extinction learning is not recalled even when specific cues no longer predict threat. Indeed, some studies have reported impaired extinction in several anxiety disorders, such as PTSD (Blechert et al, 2007; Milad et al, 2008; Orr et al, 2000; Peri et al, 2000; Wessa and Flor, 2007). Thus, the vmPFC and hippocampus are clear regions of interest in functional neuroimaging studies of anxiety disorders.

Finally, both the animal literature and studies reviewed above suggest that the dACC (and its likely homolog prelimbic cortex) and insular cortex respond to emotional 
stimuli or those that predict threat. As with the amygdala, hippocampus, and vmPFC, these regions are involved in multiple other functions; however, they might also have important roles in specific aspects of anxiety. For example, the insular cortex is thought to mediate the monitoring of internal body states, and has been found to be hyperresponsive in anxiety-prone individuals (Paulus and Stein, 2006). In summary, research on healthy individuals has suggested that all of these brain regions are prime candidates to examine in patients with anxiety disorders.

\section{STRESS}

An important and often overlooked aspect of the fear/ anxiety neurocircuitry is its overlap and interaction with the neurocircuitry that orchestrates the stress response. It is important to note that the concept of 'stress' used here is relatively specific. It does not encompass general concepts of 'subjective distress' or 'performance load.' Although these are useful concepts, they are heterogeneous by nature and are not likely to be associated with a specific neurocircuitry. On the other hand, the concept of a stress system that leads to activation of limbic-hypothalamopituitary-adrenal axis (LHPA) and secretion of stress hormones like corticotropin-releasing hormone (CRH), adrenocorticotropic hormone, and cortisol is quite specific and is likely to be highly relevant to the neurocircuitry of fear and anxiety. The neurocircuitry governing LHPA activation has been the focus of intense studies in rodents, primates, and humans because it has been repeatedly linked to the neurobiology of mood disorders (which is addressed in detail elsewhere in this volume), but the evidence linking LHPA axis abnormalities to anxiety disorders has been less consistent, sometimes confusing, and often oversimplified. At the same time, some of the same brain regions are implicated in both anxiety and stress responses, suggesting that these responses are interrelated and can influence each other. Furthermore, anxiety and mood disorders are highly comorbid, suggesting that some common abnormalities in neurocircuitry might be present in both disorders. In the following few paragraphs, we briefly address only the structural overlap in neurocircuits and the effects of stress system activation (or stress hormones) on anxiety/fear neurocircuitry.

Epidemiologically, major depression is highly comorbid with anxiety disorders like PTSD, panic disorder, and social phobia (Reiger et al, 1990), and anxiety symptoms are highly prevalent in depression (Frances et al, 1990). Furthermore, major subcortical components of the LHPA axis (eg, hypothalamus, hippocampus, amygdala, and BNST) have also been identified as key components of anxiety/fear neurocircuitry (albeit sometimes involving different subnuclei, for example paraventricular nuclei $v s$ ventromedial hypothalamus for LHPA and fear neurocircuitry, respectively). More recently with the introduction of in vivo imaging methodologies in LHPA/stress research, the role of cortical structures like the insula and dorsal mPFC in the activation and inhibition of stress response, respectively, has been reported (Liberzon and Martis, 2006) as well as the role of subgenual ACC in self-induced sadness and depression (Mayberg et al, 1999). Together, these findings suggest a significant overlap in structures involved in the stress response and those involved in fear/anxiety responses (eg medial prefrontal cortex, insula, amygdala, hippocampus, and BNST). Finally, with respect to neurotransmitters involved, CRH is likely involved in the orchestration of both LHPA axis activity and many anxiety/fear responses. (For a review see Heim and Nemeroff, 2001.)

The activation of these overlapping regions in functional neuroimaging studies does not necessarily signify, however, activation of both the fear/anxiety response and the LHPA axis. As a matter of fact, activation of fear/anxiety does not necessarily activate an LHPA stress response, even in highly fearful (phobic) individuals (Curtis et al, 1976). In turn, activation of LHPA axis is not necessarily experienced subjectively as fear or anxiety. For example, morning awakening, food intake, and nausea all lead to LHPA axis activation without notable increases in subjective sense of fear. It is becoming increasingly clear that specific characteristics of experience (novelty, control, social support, etc.) are more salient for LHPA axis activation than degree of subjective distress or fear (Abelson et al, 2007). These facts help to better understand the findings of non-specific, or even sometimes counterintuitive, findings regarding the LHPA and stress responses in anxiety disorders such as panic disorder (Abelson et al, 2007) and PTSD (Yehuda, 2006; Yehuda et al, 1991). This also suggests that activation in specific cortical regions like mPFC or insula cannot be readily interpreted as a component of the fear response, and has to be considered within a context of a specific experiment, subjective report, symptoms, neuroendocrine profile, etc.

With these caveats in mind, important findings about stress exposure and LHPA axis activation affecting fear/ anxiety responses have been accumulating. These can be seen in two general categories: (1) the immediate effects of stress or of stress hormones on fear/anxiety responses (eg, stress or stress hormone exposure immediately precedes, or is present during the fear/anxiety responses), and (2) delayed or developmental effects, (eg, stress exposure during developmentally sensitive periods, like early childhood, modulates fear/anxiety responses later in life). In the former category, it has been reported that exposure to acute stress in healthy individuals potentiates the anxiety response (Grillon et al, 2007). In addition, stress exposure (Trier Social Stress Test) led to enhanced galvanic skin responses to conditioned stimuli $(\mathrm{CS}+)$ during fear conditioning (Jackson et al, 2006). Interestingly, stress modulates fear responses differentially in men and women. Differential effects of stress on fear/anxiety in females $v s$ males also have been demonstrated in animal studies. 
Chronic stress exposure led to impaired extinction recall of fear conditioning in male but not female rats (Baran et al, 2009). Stress exposure in animal studies also led to enhancement in contextual fear conditioning (Cordero et al, 2003). The effects of stress hormone exposure are somewhat more difficult to interpret because higher endogenous cortisol levels were associated with higher skin conductance responses (SCR) (Jackson et al, 2006), whereas administration of exogenous cortisol led to decreased SCR (Stark et al, 2006).

With respect to delayed effects of stress during the vulnerable developmental period, the findings are somewhat complex. Studies of early maternal separation in rodents (Plotsky and Meaney, 1993) and variable foraging in primates (Coplan et al, 1996) have revealed long-term alteration in stress axis responses and key neurotransmitter systems (for review see Heim and Nemeroff, 2001). In addition, recent findings of gene-by-environment interactions in PTSD (Binder et al, 2008) also point toward the possibility that early childhood experience might modify fear/anxiety neurocircuitry and contribute to the development of anxiety disorders. Direct evidence of these effects on fear/anxiety behavior is less convincing, however, as maternal separation in rat pups, which did alter relevant neurotransmitter systems, did not result in significantly enhanced startle response or decreased open field exploration as compared with non-separated animals (Caldji et al, 2000). Similarly, mixed results have been obtained in other studies where rats exposed to severe sporadic stress spent more time in open arms of an elevated plus maze but displayed increases in defensive probe burying behavior. Furthermore, animals exposed to milder chronic stress showed opposite changes (Pohl et al, 2007).

The character of the stress exposure (mild $v s$ severe, prolonged $v s$ short, predictable $v s$ non-predictable) and the sex of the individual emerge as important variables that can define the long-term effects of stress exposure, but more experimental data are clearly needed. Similarly, little is known about the specific mechanisms by which stress exposure modulates fear/anxiety circuitry. It has been suggested, as stated above, that early developmental stress exposure alters fear/anxiety circuitry via altered sensitivity and responsivity of the $\mathrm{CRH}$ and adrenergic systems, and recent advances in morphological work had suggested a potential mechanism for the effects of stress on fear conditioning and extinction. Chronic stress decreases dendritic branching in the hippocampus (McEwen, 2001) and mPFC (Liston et al, 2006; Radley et al, 2004), but increases dendritic branching in the amygdala (Mitra et al, 2005; Vyas et al, 2006). This pattern could lead to increased conditioning and impaired extinction, and both of these processes could contribute changes in anxiety/fear-related behaviors. Future research addressing these important questions will be needed to fully understand the impact of stress/LHPA axis activation on fear/anxiety and the underlying neurocircuitry.

\section{ANXIETY DISORDERS}

\section{Posttraumatic Stress Disorder}

PTSD can develop in individuals who (1) were exposed to an event or events that involved the threat of death or serious injury and (2) reacted with intense fear, helplessness or horror (APA, 2000). Individuals with PTSD reexperience the traumatic event in the form of nightmares, intrusive recollections, flashbacks, and physiological arousal and distress in response to reminders of trauma. These patients may attempt to avoid reminders of the trauma and may experience a restricted range of effect, especially positive effect. Finally, patients with PTSD report hyperarousal symptoms, such as hypervigilance, exaggerated startle, and difficulty sleeping or concentrating (APA, 2000).

Neurocircuitry models of PTSD implicate the amygdala, mPFC, and hippocampus (Rauch et al, 1998b, 2006). According to some models, the amygdala is hyperresponsive in PTSD, which may account for exaggerated fear responses and the persistence of traumatic memories. In addition, portions of the vmPFC (including the rACC) are hyporesponsive and fail to inhibit the amygdala. It is not clear which of the two regions 'drives' the overall outcome, but a hyperresponsive amygdala and hyporesponsive $\mathrm{mPFC}$ may potentially lead to deficits in extinction, emotion regulation, attention, and contextual processing (Liberzon and Sripada, 2008). Abnormal hippocampal function may contribute to deficits in contextual processing, as well as impairments in memory and neuroendocrine dysregulation. Although not originally included in early neurocircuitry models, the dACC and insular cortex may have a role in PTSD as well. Recent studies have suggested that the dACC is hyperresponsive in PTSD, perhaps underlying exaggerated fear learning. Finally, the insular cortex appears to be hyperresponsive in PTSD and other anxiety disorders, consistent with the notion that the insula may mediate anxiety proneness (Paulus and Stein, 2006; Simmons et al, 2006). (For other models, see Elzinga and Bremner, 2002; Hamner et al, 1999; Layton and Krikorian, 2002.)

Amygdala. Several studies have reported increased amygdala activation in PTSD relative to comparison groups in response to trauma-related imagery (Shin et al, 1997; Shin et al, 2004a), combat-related sounds or smells (Liberzon et al, 1999; Pissiota et al, 2002; Vermetten et al, 2007), trauma-related photographs or words (Driessen et al, 2004; Hendler et al, 2003; Morey et al, 2009; Protopopescu et al, 2005), fear conditioning (Bremner et al, 2005), and fearful facial expressions (Bryant et al, 2008b; Rauch et al, 2000; Shin et al, 2005; Williams et al, 2006). Exaggerated amygdala activation in PTSD has also been found at rest (Chung et al, 2006; Semple et al, 2000) and during the completion of neutral attention and memory tasks (Bryant et al, 2005; Shin et al, 2004b). Several studies, however, have found no differential response in the amygdala in PTSD (eg, Bremner et al, 1999a; Lanius et al, 2001) or even decreased responsivity to negative stimuli (Phan et al, 2006a). Interestingly, resilience to PTSD may be associated with 
relatively decreased amygdala activation (Britton et al, 2005; Osuch et al, 2008), and amygdala lesions may reduce the occurrence of PTSD (Koenigs et al, 2008). In support of the potential role of amygdala in PTSD, some studies have reported that amygdala activation is positively correlated with PTSD symptom severity (Armony et al, 2005; Dickie et al, 2008; Pissiota et al, 2002; Protopopescu et al, 2005; Rauch et al, 2000; Shin et al, 2004a). Similarly, response to cognitive-behavioral treatment is associated with a decrease in amygdala activation (Felmingham et al, 2007; Peres et al, 2007), and relatively higher pre-treatment amygdala activation is predictive of a less favorable response to cognitivebehavioral therapy (Bryant et al, 2008a).

Relatively few studies have examined amygdala structure and neurochemistry in PTSD. Two studies have reported trends for smaller amygdala volumes in PTSD (Bremner et al, 1997; Wignall et al, 2004), but several others have not (Bonne et al, 2001; De Bellis et al, 2001a; FennemaNotestine et al, 2002; Gilbertson et al, 2002; Gurvits et al, 1996; Lindauer et al, 2004b). One recent study using PET and ${ }^{11} \mathrm{C}$-carfentanil has reported diminished mu-opioid receptor binding in the extended amygdala in traumaexposed individuals with $v s$ without PTSD (Liberzon et al, 2007b). Another study has found decreased $\left[{ }^{11} \mathrm{C}\right]$ flumazenil binding in the left amygdala in PTSD subjects compared with trauma-exposed control participants, consistent with altered GABAergic function in this disorder (Geuze et al, 2008a), although two other studies have not reported this finding (Bremner et al, 2000a; Fujita et al, 2004).

Medial prefrontal cortex. Functional neuroimaging studies of PTSD have reported decreased activation or failure to activate the mPFC (including the rACC, medial frontal gyrus, and subcallosal cortex) during traumatic scriptdriven imagery (Bremner et al, 1999a; Britton et al, 2005; Lanius et al, 2001; Lindauer et al, 2004a; Shin et al, 1999, 2004a), the presentation of trauma-related stimuli (Bremner et al, 1999b; Hou et al, 2007; Yang et al, 2004), and negative, non-traumatic stimuli (Kim et al, 2007; Lanius et al, 2003; Phan et al, 2006a; Shin et al, 2005; Williams et al, 2006). Relatively diminished activation of the MPFC in PTSD also has been shown during extinction (Bremner et al, 2005), emotional Stroop interference (Bremner et al, 2004; Shin et al, 2001), emotional word retrieval (Bremner et al, 2003b), non-emotional cognitive tasks (Bryant et al, 2005; Semple et al, 2000) and at rest (Semple et al, 2000). Furthermore, mPFC activation appears to be inversely correlated with PTSD symptom severity (Britton et al, 2005; Dickie et al, 2008; Hopper et al, 2007; Kim et al, 2007; Shin et al, 2004a, 2005; Williams et al, 2006) and positively correlated with pre-scan cortisol levels (Liberzon et al, 2007a). Finally, increased mPFC activation following treatment has been positively associated with symptomatic improvement (Felmingham et al, 2007; Lansing et al, 2005; Peres et al, 2007; Seedat et al, 2004), although not all studies have shown this, perhaps due to paradigm-related methodological differences (Bryant et al, 2008a).

Most of the findings summarized above reflect activation peaks in rostral ACC and ventral portions of the mPFC. In contrast, more dorsal regions of the ACC (ie, the dACC) appear to have either normal or exaggerated responsivity in PTSD during fear conditioning, interference tasks, an auditory oddball task, and at rest (Bremner et al, 2005; Bryant et al, 2005; Felmingham et al, 2009; Pannu Hayes et al, 2009; Shin et al, 2001, 2007, in press).

The findings of several studies suggest diminished volumes or gray matter densities in the ACC in PTSD (Corbo et al, 2005; Kasai et al, 2008; Rauch et al, 2003; Woodward et al, 2006; Yamasue et al, 2003), and smaller ACC volumes have been associated with greater PTSD symptom severity (Woodward et al, 2006; Yamasue et al, 2003). In a study of monozygotic twins discordant for trauma exposure, diminished gray matter densities in pregenual ACC were not found in the identical twins of the PTSD participants, suggesting that this gray matter density decrease is likely an acquired sign of the disorder rather than a familial risk factor (Kasai et al, 2008).

Magnetic resonance spectroscopy (MRS) studies have revealed diminished $\mathrm{N}$-acetyl aspartate (NAA) levels in the ACC in PTSD (De Bellis et al, 2001b, b; Ham et al, 2007a; Mahmutyazicioglu et al, 2005; Schuff et al, 2008). Furthermore, NAA levels in the pregenual ACC were negatively correlated with the severity of reexperiencing symptoms (Ham et al, 2007a). Two recent studies have reported decreased benzodiazepine receptor binding in the $\mathrm{MPFC}$ in PTSD (Bremner et al, 2000a; Geuze et al, 2008a), although one other study failed to find this effect (Fujita et al, 2004).

Hippocampus. Some functional neuroimaging studies have reported decreased hippocampal activation during symptomatic states (Bremner et al, 1999a) and during memory tasks that involve neutral or emotional stimuli (Astur et al, 2006; Bremner et al, 2003a, b; Moores et al, 2008; Shin et al, $2004 \mathrm{~b})$. One study found reduced glucose metabolic rate in the hippocampus at rest (Molina et al, 2007), and another reported that successful treatment was related to increased hippocampal activation (Peres et al, 2007). Other studies, however, have reported increased activation in the hippocampus in PTSD (Geuze et al, 2007, 2008b; Sachinvala et al, 2000; Semple et al, 2000; Thomaes et al, 2009; Werner et al, 2009) or a positive correlation between hippocampal activation and PTSD symptom severity (Osuch et al, 2001; Shin et al, 2004b). The direction of hippocampal functional abnormalities appears to depend in part on the type of task and the type of statistical analysis used.

Hippocampal volumes appear to be diminished in PTSD in some (Bossini et al, 2008; Bremner et al, 1995, 1997, 2003a; Gilbertson et al, 2002; Gurvits et al, 1996; Karl et al, 2006; Kitayama et al, 2005; Smith, 2005; Stein et al, 1997; Villarreal et al, 2002a; Wignall et al, 2004; Winter and Irle, 2004; Woon and Hedges, 2008), but not all studies (Bonne et al, 2001; Carrion et al, 2001; De Bellis et al, 1999, 2002; Fennema-Notestine et al, 2002; Golier et al, 2005; Pederson et al, 2004). Hippocampal volumes have been inversely associated with verbal memory deficits (Bremner et al, 1995), combat exposure severity (Gurvits et al, 1996), dissociative symptom severity (Bremner et al, 2003a; Stein et al, 1997), depression severity (Villarreal et al, 2002a), and 
PTSD symptom severity (Bremner et al, 2003a; Gilbertson et al, 2002; Villarreal et al, 2002a). Spectroscopy studies of hippocampus have reported decreased NAA in the hippocampus, often interpreted as consistent with decreased neuronal integrity (Brown et al, 2003; Freeman et al, 1998; Ham et al, 2007a; Mohanakrishnan Menon et al, 2003; Schuff et al, 2001; Villarreal et al, 2002b). The results of two studies suggest that hippocampal volumes may increase following treatment with serotonin reuptake inhibitors (Bossini et al, 2007; Vermetten et al, 2003).

Whether decreased volumes can explain abnormal hippocampal activation in PTSD is not entirely clear, although the findings of at least two studies suggest that functional abnormalities might be still present even if the volumetric differences are controlled statistically (Bremner et al, 2003a; Shin et al, 2004b). The origin of decreased hippocampal volumes is not known, although the results of one twin study suggest that diminished hippocampal volumes may be a familial risk factor for developing PTSD following psychological trauma (Gilbertson et al, 2002).

With regard to neurochemistry, one recent PET study found decreased $\left[{ }^{11} \mathrm{C}\right]$ flumazenil binding in the hippocampus (as well as thalamus and cortical areas) suggesting diminished benzodiazepine- $\mathrm{GABA}_{\mathrm{A}}$ function in the hippocampus in PTSD (Geuze et al, 2008a).

Insular cortex. Relative to comparison groups, increased activation in the insular cortex has been found in PTSD during script-driven imagery (Lanius et al, 2007; Lindauer et al, 2008), fear conditioning and extinction (Bremner $\mathrm{et} \mathrm{al}$, 2005), the anticipation of negative images (Simmons et al, 2008), the retrieval of emotional or neutral stimuli (Bremner et al, 2003b; Werner et al, 2009; Whalley et al, 2009), aversive smells and painful stimuli (Geuze et al, 2007; Vermetten et al, 2007), and the performance of an emotional Stroop task (Shin et al, 2001). Insular cortex activation has been found to be positively correlated with measures of symptom severity (Carrion et al, 2008; Hopper et al, 2007; Osuch et al, 2001) and post-scan plasma adrenocorticotropic hormone levels (Liberzon et al, 2007a). Although greater insular activation in PTSD has been confirmed by a recent voxel-wise meta-analysis (Etkin and Wager, 2007), a few studies have reported either no group differences in insular activation or relatively decreased activation in PTSD (Bremner et al, 1999a, 2004; Molina et al, 2007; Moores et al, 2008; Phan et al, 2006a; Shin et al, 1999).

Voxel-based morphometry studies of PTSD have reported reduced gray matter density in the insular cortex (Chen et al, 2006; Corbo et al, 2005; Kasai et al, 2008). In one study, gray matter density in the insular cortex was negatively correlated with reexperiencing; that is, lower gray matter density was associated with greater reexperiencing (Kasai et al, 2008).

One recent PET- $\left[{ }^{11} \mathrm{C}\right]$ flumazenil study has reported decreased benzodiazepine- $\mathrm{GABA}_{\mathrm{A}}$ receptor binding in bilateral insular cortex in PTSD (Geuze et al, 2008a).

Summary. In general, the functional neuroimaging findings in PTSD support the hypothesis that the amygdala is hyperresponsive and ventral portions of medial prefrontal cortex are hyporesponsive, at least in some groups of PTSD patients. Indeed, the latter finding appears to be one of the most robust in the literature (Etkin and Wager, 2007) (Table 1). In addition, albeit in a small number of studies, reduced volumes and gray matter densities in the ACC have been fairly consistently reported. Furthermore, emerging evidence suggests that the dACC and insular cortex may be hyperresponsive in PTSD, although insular cortex hyperresponsivity does not appear to be specific to PTSD (Etkin and Wager, 2007). Finally, the majority of studies have found diminished hippocampal volumes in PTSD patients. Hippocampal function appears to be abnormal as well, although the direction of the abnormality seems to depend on the type of task completed during neuroimaging.

\section{Panic Disorder}

Panic disorder patients experience recurrent, unexpected panic attacks, along with a persistent concern about having future attacks, or worry about the implications of the attacks, or a significant change in behavior related to the attacks (APA, 2000). A panic attack is a discrete episode of intense fear, discomfort, and sympathetic nervous system arousal that occurs in the absence of true danger (APA, 2000). According to one of the neurocircuitry models of panic disorder, the 'fear network,' which includes the

Table 1 Summary of the Direction of Functional Neuroimaging Findings in Anxiety Disorders

\begin{tabular}{lcccc}
\hline & Amygdala & rACC & dACC & Hippocampus \\
\hline Posttraumatic stress disorder & $\uparrow$ & $\downarrow$ & $\uparrow^{*}$ & $\uparrow \downarrow$ \\
Panic disorder & $\uparrow \downarrow^{*}$ & $\uparrow^{*}$ & - & $\uparrow \downarrow$ \\
Social phobia & $\uparrow$ & $\uparrow \downarrow^{*}$ & $\uparrow \downarrow$ & - \\
Specific phobia & $\uparrow$ & $\uparrow \downarrow^{*}$ & $\uparrow$ & - \\
Generalized anxiety disorder & $\uparrow \downarrow^{*}$ & $\uparrow^{*}$ & $\uparrow^{*}$ & - \\
\hline
\end{tabular}

$\mathrm{rACC}=$ rostral anterior cingulate cortex; $\mathrm{dACC}=$ dorsal anterior cingulate cortex

$\uparrow=$ increased function in the disorder (relative to control groups).

$\downarrow=$ decreased function in the disorder (relative to control groups).

$\uparrow \downarrow=$ mixed findings.

* = based on a very small number of studies.

- = too little information available. 
amygdala, hippocampus, thalamus, and brain stem structures, is hypersensitive. Furthermore, frontal cortex fails to provide top-down inhibitory input to the amygdala, leading to exaggerated amygdala activation and unnecessary activation of the entire fear network, resulting in a panic attack (Coplan and Lydiard, 1998; Gorman et al, 2000). This type of model is similar to the models proposed for other anxiety disorders such as PTSD. Indeed, PTSD patients often suffer from comorbid panic attacks (Falsetti and Resnick, 1997). Although it is quite possible that PTSD and panic disorder indeed share similar pathophysiological components, it will be important in the future to identify abnormalities that are disorder specific and are responsible for disorder-specific symptomatology.

Amygdala. Hyperactivation of the amygdala in panic disorder has been reported in response to panic-related words (van den Heuvel et al, 2005b) and neutral faces (Pillay et al, 2007). One recent PET study found greater resting glucose metabolism in the amygdala (Sakai et al, 2005), although amygdala glucose metabolism did not change after effective treatment with cognitive-behavioral therapy (Sakai et al, 2006). The possibility that amygdala hyperactivation is present in a subgroup of panic disorder patients has been supported by recent studies examining the effect of genotypes within patients with panic disorder. These have revealed greater amygdala activation in carriers of the COMT 158val allele (Domschke et al, 2008), the 5-HT1A x1019 GG allele, and the short allele of the serotonin transporter polymorphism (Domschke et al, 2006). In contrast, two studies found relatively decreased amygdala activation during anticipatory anxiety (Boshuisen et al, 2002) and in response to fearful facial expressions (Pillay et al, 2006), although the latter finding may be attributed to the fact that panic disorder patients were taking antidepressants, which have been found to decrease amygdala activation (Harmer et al, 2006).

The volumetric findings in the amygdala of panic disorder patients are very sparse. One study reported smaller bilateral amygdala volumes in panic disorder compared with healthy participants (Massana et al, 2003). The same group reported reduced levels of creatine and phosphocreatine in the right medial temporal lobe (including the amygdala and part of the hippocampus) in panic disorder. This was interpreted as potentially representing a hypermetabolic state in the right medial temporal region (Massana et al, 2002), which would be consistent with the findings of Sakai et al (2005). Finally, with respect to relevant neurotransmission findings, SPECT and PET studies have reported decreased GABA-benzodiazepine receptor binding in the medial temporal lobes (Kaschka et al, 1995; Malizia et al, 1998) and decreased 5-HT1 $1_{\mathrm{A}}$ receptor binding in the amygdala in panic disorder (Nash et al, 2008).

Medial prefrontal cortex. Consistent with the literature on pharmacologically induced fear and panic in healthy volunteers, studies of panic disorder have revealed increased rACC activation during imagery of high vs low anxiety situations (Bystritsky et al, 2001), anticipatory anxiety (Boshuisen et al, 2002), and in response to happy faces in panic disorder (Pillay et al, 2007), although medication was a potential confound in the latter study. Dorsal ACC hyperresponsivity has also been reported in panic disorder in one study (Pillay et al, 2007). Panic disorder patients who are carriers of the COMT 158val allele appear to have less medial prefrontal deactivation and greater orbitofrontal activation in response to emotional facial expressions (Domschke et al, 2008). In contrast, panic disorder subjects with the 5-HT1A x1019 GG allele had less ACC, medial prefrontal cortex, and orbitofrontal activation in response to fearful facial expressions (Domschke et al, 2006).

Volumetric evidence is again sparse, but it appears that both dACC and rACC might be exhibiting similar types of change. Gray matter volumes appear to be reduced in the rACC (Asami et al, 2008; Uchida et al, 2008) and dACC (Asami et al, 2008), and white matter integrity, as measured by DTI, appears to be enhanced in the rACC in panic disorder (Han et al, 2008).

Two studies have reported decreased $\mathrm{GABA}_{\mathrm{A}}$-benzodiazepine receptor binding in the ACC and medial prefrontal cortex, including in the dACC (Hasler et al, 2008; Malizia et al, 1998), and one study found a negative correlation between panic attack symptom severity and benzodiazepine receptor binding in dorsal medial frontal gyrus (Bremner et al, 2000b). An MRS study reported increased lactate and choline levels in the rACC (Ham et al, 2007b), and two PET studies have reported decreased $5-\mathrm{HT}_{\mathrm{A}}$ receptor binding in the anterior cingulate in panic disorder (Nash et al, 2008; Neumeister et al, 2004).

Hippocampus. The evidence for hippocampal involvement in panic disorder comes mainly from studies of metabolism and perfusion. Two PET studies of panic disorder have reported abnormalities in the laterality of hippocampal resting glucose metabolic rates (Nordahl et al, 1990, 1998), and two PET studies have found greater resting glucose metabolism in the hippocampus in patients with panic disorder (Bisaga et al, 1998; Sakai et al, 2005). In contrast, a SPECT study has reported reduced perfusion in the hippocampus in panic disorder (De Cristofaro et al, 1993). Two studies have reported decreased $\mathrm{GABA}_{\mathrm{A}^{-}}$ benzodiazepine receptor binding in the hippocampus (Bremner et al, 2000b; Malizia et al, 1998), and one study has reported the opposite finding (Hasler et al, 2008).

Insular cortex. With regard to the insular cortex in panic disorder, studies have reported decreased activity during anticipatory anxiety (Boshuisen et al, 2002), increased gray matter volume (Protopopescu et al, 2006; Uchida et al, 2008), decreased $5-\mathrm{HT} 1_{\mathrm{A}}$ receptor binding (Nash et al, 2008), and decreased $\mathrm{GABA}_{\mathrm{A}}$-benzodiazepine receptor binding (Malizia et al, 1998).

Brain stem. Functional neuroimaging studies have reported increased glucose metabolic rates (Sakai et al, 2005) and increased activity during anticipatory anxiety (Boshuisen et $a l, 2002)$ in the brain stem in panic disorder. Gray matter 
volume appears to be increased in the midbrain and pons (Protopopescu et al, 2006; Uchida et al, 2008). Decreased $\mathrm{GABA}_{\mathrm{A}}$-benzodiazepine receptor binding was reported in the pons (Malizia et al, 1998), and two studies have found decreased $5-\mathrm{HT} 1_{\mathrm{A}}$ receptor binding in the raphe nucleus in panic disorder (Nash et al, 2008; Neumeister et al, 2004).

Summary. Several studies have provided evidence consistent with amygdala and brain stem hyperresponsivity in panic disorder. Activation in rACC and dACC appears to be increased, and gray matter volumes in these regions appear to be decreased. Several studies have reported decreased $\mathrm{GABA}_{\mathrm{A}}$-benzodiazepine and $5-\mathrm{HT}_{1 \mathrm{~A}}$ receptor binding in the amygdala, medial prefrontal cortex, insular cortex, and brain stem in panic disorder. A common limitation seen in several neuroimaging studies of this disorder is the inclusion of participants taking psychiatric medications (Domschke et al, 2006, 2008; Han et al, 2008; Pillay et al, 2006, 2007; Uchida et al, 2008). Thus, the findings of such studies should be interpreted cautiously pending replication in medication-free participants.

\section{Social Phobia}

Social phobia (or social anxiety disorder) is characterized by a marked and persistent fear of social or performance situations involving possible scrutiny by others (APA, 2000). The fear of embarrassment and distress can lead to avoidance of social situations and impairment in social, occupational, and academic functioning. The amygdala and medial prefrontal cortex have been considered important regions of interest in this disorder (Amaral, 2002; Liebowitz et al, 2005; Mathew et al, 2001; Stein et al, 2002a; Stein, 1998).

Amygdala. Exaggerated amygdala responses in social phobia have been observed during public speaking (Tillfors et al, 2001), the anticipation of public speaking (Lorberbaum et al, 2004; Tillfors et al, 2002), negative comments (Blair et al, 2008a), and in response to neutral, angry, contemptuous, happy, and schematic angry facial expressions (Birbaumer et al, 1998; Blair et al, 2008b; Cooney et al, 2006; Evans et al, 2008; Gentili et al, 2008; Guyer et al, 2008; Phan et al, 2006b; Schneider et al, 1999; Stein et al, 2002b; Straube et al, 2004a, 2005; Veit et al, 2002; Yoon et al, 2007). One study found temporally delayed amygdala responses to faces in a social phobia group compared with a healthy control group (Campbell et al, 2007). In addition, amygdala responses in social phobia have been positively correlated with self-reported fear increases (Tillfors et al, 2001), severity of social anxiety symptoms (Blair et al, 2008b; Evans et al, 2008; Guyer et al, 2008; Phan et al, 2006b), and state-trait anxiety scores (Cooney et al, 2006). The genetic predisposition for social phobia has been supported by the finding that social phobia patients with a short allele of the serotonin transporter polymorphism had greater amygdala responses during public speaking compared to those with long alleles (Furmark et al, 2004). Finally, amygdala activation during public speaking in social phobia appears to decrease with successful treatment (Furmark et al, 2002, 2005). In contrast, one recent study found decreased amygdala activation during script-driven imagery of anxiety-provoking social situations and a mental arithmetic task in social phobia (Kilts et al, 2006). One study has reported reduced 5- $\mathrm{HT}_{1 \mathrm{~A}}$ receptor binding in the amygdala in this disorder (Lanzenberger et al, 2007).

Medial prefrontal cortex. Exaggerated rACC activation in social phobia has been found in response to facial expressions of fear (Blair et al, 2008b) and disgust (Amir et al, 2005), and in response to pictures of peers with whom patients did not want to interact (Guyer et al, 2008). One study reported greater orbitofrontal cortex activation to angry $v s$ neutral prosody (Quadflieg et al, 2008). In contrast, other studies have found decreased activation (Van Ameringen et al, 2004) and decreased glucose metabolic rates in the ventromedial prefrontal cortex (Evans et al, 2009), which increased following treatment with tiagabine (Evans et al, 2009). Glutamate/creatine and NAA/creatine ratios appear to be elevated in the rACC and are correlated with symptom severity (Phan et al, 2005).

Studies of dACC function in social phobia also have been somewhat mixed. Greater dACC activation has been reported in response to negative comments (Blair et al, 2008a) and harsh or disgusted facial expressions (Amir et al, 2005; Phan et al, 2006b). Another study reported greater dorsal medial frontal activation in response to harsh faces (Stein et al, 2002b). Treatment with nefazodonedecreased activation in dACC (Kilts et al, 2006). In contrast, other studies have found decreased dACC activation to schematic angry faces (Evans et al, 2008) and in anticipation of public speaking (Lorberbaum et al, 2004), as well as decreased glucose metabolism at rest (Evans et al, 2009). One study found temporally delayed medial prefrontal cortex/dACC responses to faces in social phobia, which may help to account for the heterogeneity of findings in the literature regarding this structure (Campbell et al, 2007). Finally, one study reported reduced $5-\mathrm{HT}_{1 \mathrm{~A}}$ receptor binding in the anterior cingulate in social phobia, although whether this finding occurred in the dorsal or rostral ACC was not specified (Lanzenberger et al, 2007).

Insular cortex. Insular cortex activation appears to be elevated in social phobia during the anticipation of public speaking (Lorberbaum et al, 2004) and in response to emotional facial expressions (Amir et al, 2005; Gentili et al, 2008; Straube et al, 2004a, 2005; Yoon et al, 2007), including schematic facial expressions (Evans et al, 2008; Straube et al, 2004a). Two studies, however, found decreased insular cortex activation during public speaking (Tillfors et al, 2001) and during an implicit sequence-learning task in social phobia (Sareen et al, 2007). One study has found reduced $5-\mathrm{HT}_{1 \mathrm{~A}}$ receptor binding in the insular cortex in this disorder (Lanzenberger et al, 2007).

Striatum. One recent study has found reduced caudate activation during an implicit sequence-learning task in generalized social phobia (Sareen et al, 2007). Other studies have found reduced $\mathrm{D}_{2}$ receptor binding and dopamine transporter densities in the striatum in social phobia (Schneier et al, 2000; Tiihonen et al, 1997), although a 
recent study failed to replicate these findings (Schneier $e t$ al, 2009).

Summary. Exaggerated amygdala activation has been the most consistent functional neuroimaging finding in the social phobia literature. Although several studies have reported exaggerated rACC and insular cortex activation as well, a number of other studies have reported contradictory findings. Future research will have to: (1) address questions regarding $\mathrm{ACC} / \mathrm{mPFC}$ and insular involvement, potentially utilizing cognitive activation tasks to probe ACC function, and (2) attempt to identify the neurocircuitry specific to social phobia (eg, the regions that contribute to the perception/interpretation of social stimuli as particularly anxiety/fear inducing).

\section{Specific Phobia}

Specific phobias are marked by excessive, unreasonable and persistent fear of specific objects or situations such as small animals, flying, enclosed places, heights, and blood/injury (APA, 2000). The fear and avoidance causes significant distress and/or impairment in occupational, academic, or social functioning. Specific phobia is a relatively common disorder, with a lifetime prevalence of 7-11\% (APA, 2000). Early models of the etiology of phobias centered on fear conditioning and extinction, and therefore implicated the amygdala and medial prefrontal cortex. Admittedly, such fear conditioning models are likely to be incomplete given that (1) many individuals with phobias cannot recall a conditioning event, and (2) only a small number of common stimuli or situations are the objects of phobias (Fyer, 1998). Nevertheless, fear conditioning and extinction models have been useful in guiding neuroimaging researchers toward examining amygdala, medial prefrontal cortex, and insular cortex function in this disorder.

Amygdala. Exaggerated amygdala activation in individuals with specific phobia has been observed in response to phobia-related pictures (Dilger et al, 2003; Goossens et al, 2007a, b; Schienle et al, 2005, 2007; Straube et al, 2006b; Veltman et al, 2004; Wendt et al, 2008). In addition, treatment has been associated with decreased amygdala activation (Goossens et al, 2007b; Schienle et al, 2007). However, numerous studies have not reported exaggerated amygdala activation in specific phobia (Hermann et al, 2007; Larson et al, 2006; Paquette et al, 2003; Straube et al, 2004b, 2007; Wik et al, 1996, 1997; Wright et al, 2003), perhaps in part due to methodological differences, such as the use of different imaging modalities, type of stimuli (verbal $v s$ pictorial), mode of presentation (video clips $v s$ stills), or phobia-unrelated facial expressions. Preliminary findings assessing the NK1 receptor have suggested enhanced levels of endogenous neuropeptide substance $\mathrm{P}$ (commonly associated with stress and negative affect) in the amygdala in phobics when presented with phobia-relevant pictures (Michelgard et al, 2007).

Medial prefrontal cortex. The findings with regard to the rACC in specific phobia are mixed, with two studies showing less rACC activation in phobia groups in response to phobia-related $v s$ neutral pictures (Hermann et al, 2007; Schienle et al, 2007), and two studies reporting enhanced rACC activation to phobia-related stimuli (Britton et al, 2009; Pissiota et al, 2003). Activation in the rACC appears to be positively correlated with anticipatory anxiety in phobia patients (Straube et al, 2007). The rACC has been shown to be thicker in participants with specific phobias relative to control participants without phobias (Rauch et al, 2004).

In contrast, the results of functional neuroimaging studies are much more consistent with regard to the dACC, which has been found to be hyperresponsive to phobia-related stimuli (Goossens et al, 2007a, b; Straube et al, 2006a, b) or the anticipation of such stimuli (Straube et al, 2007). In addition, dACC activation in specific phobia decreases after habituation (Veltman et al, 2004) and cognitive-behavioral treatment (Goossens et al, 2007b; Straube et al, 2006a).

Insular cortex. Recent research has reported exaggerated insular cortex activation in specific phobia $v s$ control cohorts in response to phobia- or fear-related pictures, videos, and words (Dilger et al, 2003; Goossens et al, 2007a, b; Schienle et al, 2005; Straube et al, 2004b, 2006b, 2007; Wendt et al, 2008), as well as fearful facial expressions (Wright et al, 2003). In addition, treatment studies have reported decreased insula activation following cognitivebehavioral treatment (Goossens et al, 2007b; Schienle et al, 2007; Straube et al, 2006a). Insular cortex also appears to be thicker (bilaterally) in participants with specific phobia as compared with healthy control participants (Rauch et al, 2004).

Summary. The amygdala, dACC and insular cortex all appear to be hyperresponsive to phobia-related stimuli in specific phobia. These abnormalities tend to normalize with successful treatment. The findings are few and mixed with regard to the rACC.

\section{Obsessive-Compulsive Disorder}

Patients with obsessive-compulsive disorder (OCD) experience recurrent, unwanted thoughts or images (obsessions) that cause distress, and engage in excessive ritualistic behaviors or mental acts (compulsions) that are typically carried out in response to the obsessions (APA, 2000). Because OCD is covered more extensively in another chapter, we only very briefly discuss it here (see also Friedlander and Desrocher, 2006; Menzies et al, 2008). In general, abnormalities in thalamo-cortico-striatal loops have been posited to account for the repetitive quality and the cognitive and motor content of the obsessions and compulsions in OCD. One neurocircuitry model of OCD posits that the striatum (caudate nucleus) functions abnormally, leading to inefficient gating in the thalamus (Graybiel and Rauch, 2000; Rauch et al, 1998a). This may lead to hyperactivity in the orbitofrontal cortex and the anterior cingulate cortex, which may mediate intrusive thoughts and anxiety, respectively. Compulsions may serve to recruit the striatum and to achieve thalamic gating, 
thereby neutralizing the obsessions and reducing anxiety. Thus, the fear/anxiety-related brain regions that we have focused on so far (eg, amygdala, mPFC, insula, and hippocampus) do not appear to mediate the core OCD symptomatology. It is interesting to note here that the neurocircuitry model of OCD is much further developed (eg, nodes, links, and directionality are better specified) than the models of other anxiety disorders. There could be a number of factors contributing to this: (1) OCD has been studied longer than other anxiety disorders; (2) The nature of OCD symptoms (for example the predominant cognitive component) implicated neurocircuitry that is better understood or is organized in a way that renders itself easier for the development of circuitry-based models. Whatever the reason might be, one of the goals for future research in other anxiety disorders should be to strive to develop neurocircuitry hypotheses that are comparable in detail and specifications to the models that are already available for OCD.

Although some functional neuroimaging studies have found elevated amygdala activation in OCD (Breiter et al, 1996b; van den Heuvel et al, 2004; Van Laere et al, 2006), the majority have not, even with facial expression paradigms that are known to activate the amygdala in healthy subjects and patients with other anxiety disorders (Cannistraro et al, 2004). The preponderance of neuroimaging studies have identified functional and/or structural abnormalities in the components of thalamo-cortico-striatal loops: striatum (Bartha et al, 1998; Baxter et al, 1987, 1988; Chen et al, 2004; Rauch et al, 1994, 1997; Remijnse et al, 2006; Robinson et al, 1995; Rosenberg et al, 1997; van den Heuvel et al, 2005a), thalamus (Atmaca et al, 2006; Chen et al, 2004; Fitzgerald et al, 2000; Gilbert et al, 2000), orbitofrontal cortex (Baxter et al, 1987, 1988; Chamberlain et al, 2008; Chen et al, 2004; Kang et al, 2004; Rauch et al, 1994; Remijnse et al, 2006; Valente et al, 2005), and the ACC (Ebert et al, 1997; Fitzgerald et al, 2005; Rauch et al, 1994; Valente et al, 2005). In addition, recent receptor imaging studies in OCD have revealed reduced serotonin transporter availability in the thalamus and midbrain (Reimold et al, 2007), as well as reduced $5-\mathrm{HT}_{2 \mathrm{~A}}$ receptor availability in the ACC and other frontal cortical areas (Perani et al, 2008). One interesting and unanswered question remains: If OCD is indeed associated with very high anxiety states, especially linked to specific worries or compulsions, why doesn't the circuitry associated with other anxiety disorders or state anxiety in healthy controls have a more prominent role in the expression of this anxiety?

\section{Generalized Anxiety Disorder}

Generalized anxiety disorder (GAD) is characterized by excessive diffuse anxiety and worry that is difficult to control. Patients with GAD may experience restlessness, fatigue, irritability, muscle tension, and sleep and concentration difficulties (APA, 2000). Relatively few neuroimaging studies of GAD exist in the literature and some of the findings are conflicting; however, some studies have implicated the amygdala and medial prefrontal cortex in this disorder.

Amygdala. Exaggerated amygdala activation in response to fearful (McClure et al, 2007b) and masked angry facial expressions (Monk et al, 2008) and during the anticipation of aversive photographs (Nitschke et al, 2009) has been reported in patients with GAD. In a mixed cohort of subjects with GAD and social phobia, subjects who had a low tolerance for uncertainty had elevated amygdala activation during a decision-making task (Krain et al, 2008). In a study of adolescents with GAD, amygdala responses were positively correlated with GAD symptom severity (Monk et al, 2008). However, other studies have not found exaggerated amygdala activation in GAD (Blair et al, 2008b; Whalen et al, 2008). In a recent treatment study, greater pre-treatment left amygdala activation to fearful faces was associated with a less favorable response to venlafaxine (Whalen et al, 2008); in contrast, a different study on a pediatric GAD sample found that greater pretreatment left amygdala activation to fearful faces was associated with a more favorable response to cognitivebehavioral treatment (McClure et al, 2007a). One study has reported larger amygdala volumes in pediatric GAD (De Bellis et al, 2000a).

Medial prefrontal cortex. Although the literature is currently very small, it appears that medial prefrontal cortex activation may be elevated in GAD. Activation in dACC and rACC appears to be elevated in response to fearful facial expressions in adolescents with GAD (McClure et al, 2007b). In a mixed cohort of subjects with GAD and social phobia, those with higher intolerance for uncertainty had elevated rACC and subgenual ACC activation during a decision-making task (Krain et al, 2008). In addition, dorsal ACC activation in response to worry vs neutral statements declined significantly after treatment with citalopram (Hoehn-Saric et al, 2004). Finally, greater pre-treatment rACC activation in response to fearful facial expressions (Whalen et al, 2008) and the anticipation of emotional stimuli (Nitschke et al, 2009) was associated with a more favorable response to venlafaxine. Regions in lateral prefrontal cortex also appear to show exaggerated activation (Monk et al, 2006) and elevated NAA/creatine ratios in GAD (Mathew et al, 2004).

Summary. Although there is some evidence for exaggerated amygdala and medial prefrontal cortex responses in GAD, there are too few studies to form conclusions about the role of these structures in the pathophysiology of GAD. Future functional neuroimaging studies using fearful facial expressions and tasks that probe medial prefrontal cortex function (eg, extinction, emotion regulation, or interference tasks) might be able to contribute the much needed additional information regarding amygdala and medial prefrontal cortex function in GAD.

\section{Summary}

Overall, the findings of functional neuroimaging studies are consistent with the notion of exaggerated amygdala 
activation to specific stimuli in a number of anxiety disorders, especially social phobia, specific phobia, and PTSD. Facial expressions have been especially effective probes of amygdala responses in social phobia and PTSD. Interestingly, the data regarding amygdala function in panic disorder are still inconclusive, and given that relatively few studies have examined amygdala function in GAD, additional research is needed to make meaningful comparisons of amygdala responses between various anxiety disorders. Although increased amygdala activation has been observed in a few studies of OCD, the overall pathophysiology of OCD appears to be localized to a different brain circuit. One potential conceptualization of these findings is that amygdala hyperactivation is a common pathway for exaggerated anxiety/fear that is triggered by specific stimuli. Thus anxiety disorders that manifest increased fear/anxiety that is associated with specific identifiable stimuli (eg, PTSD, social phobia, and specific phobia) will have evidence of exaggerated amygdala reactivity. Panic attacks, on the other hand, can occur in the absence of such stimuli and might thus involve activation of other structures within fear/anxiety neurocircuitry (such as brain stem nuclei, periaqueductal gray, and $\mathrm{mPFC}$ ). If this is the case, it can explain why the degree of amygdala activation in panic disorder may vary depending on the presence of identified panic-related stimuli and/or other brain regions activated. Conceptually, the hyperresponsivity of amygdala and brain stem is consistent with cognitive and somatic manifestation of panic attacks; however, hyperactivation of the anterior cingulate is probably more consistent with compensatory/ regulatory roles rather than reflecting panic-specific pathophysiology.

Consistent with the findings of the meta-analysis of Etkin and Wager (2007), relatively diminished rACC activation has been reported fairly consistently in PTSD, but not in other anxiety disorders. Thus, relatively diminished rACC function may be specific to PTSD and could reflect abnormalities in recall/contextualization of fear memories. Activation in other regions like the AACC and insular cortex appears to be elevated in PTSD and in several of the other anxiety disorders. Exaggerated activation in these regions may reflect various aspects of anxiety/fear response, such as anticipatory anxiety, interoceptive components, autobiographic memory, or anxiety proneness (Paulus and Stein, 2006; Shin et al, in press; Simmons et al, 2006). Together these findings can be conceptualized as an evidence of hyperresponsive threat detection, autobiographic memory, and somatic/physiological reactivity systems in PTSD, accompanied by the failure in regulatory regions responsible for safety signaling, fear extinction, and stimulus appraisal, together leading to aberrant contextual processing of the threat-related stimuli.

The hippocampus was studied most frequently in PTSD and panic disorder, but rarely in the other disorders. Thus, whether similar structural and functional abnormalities in the hippocampus occur in other anxiety disorders is uncertain. Although the evidence for hippocampal involvement in memory and contextual processing is strongly supported by animal studies, and deficits in hippocampal function (eg, contextual processing) are consistent with the PTSD model outlined above, more information is needed to understand the role of the hippocampus in anxiety disorders.

However, neuroimaging studies of anxiety disorders are not without limitations. On the technical side, the spatial resolution of functional neuroimaging techniques is limited, and even those techniques with the best spatial resolution (fMRI) cannot accurately differentiate between very small adjacent structures (such as subnuclei of the amygdala). This, in addition to the presence of susceptibility artifacts (in the case of fMRI studies), makes resolution of potentially important structures, such as the hypothalamus and brain stem nuclei, particularly problematic for studies of fear/anxiety neurocircuitry. In addition, the temporal resolution of some of the imaging techniques used (ie, PET and SPECT) makes it difficult to detect quick and transient responses to stimuli. On the clinical side, the use of medications (ie, antidepressants or benzodiazepines) in patient groups can affect brain activation and represent a confounding factor. However, for regions such as the amygdala, medications tend to normalize amygdala responses rather than exaggerate them (Harmer et al, 2006; Paulus et al, 2005). Comorbidity represents a challenge as well. The majority of patients with anxiety disorders have comorbid conditions, such as depression. Although it is tempting to exclude from neuroimaging studies those anxiety disorder patients with comorbid conditions, this procedure raises concerns about the ability to generalize findings to the larger population of individuals with anxiety disorders. Recent studies have attempted to deal with this issue by separating anxiety disorder patients into groups with and without comorbidity (Kemp et al, 2007; Lanius et al, 2007).

\section{FUTURE RESEARCH DIRECTIONS}

Although much information that is relevant to the pathophysiology of anxiety disorders has been gained over the last two decades, many research questions remain to be answered. As we have noted previously, questions remain regarding the specific roles of the amygdala, medial prefrontal cortex, insula, and hippocampus in the anxiety disorders. In addition, one of the more general and basic questions is whether the functional abnormalities identified in anxiety disorders represent acquired signs of the disorders or vulnerability factors that increase the risk of developing the disorders. For example, does amygdala hyperresponsivity occur after the symptoms of social phobia, specific phobia, or PTSD appear? Or does the amygdala hyperresponsivity precede the development of symptoms and increase the risk for developing them? Two types of studies could be used to try to address these 
questions. First, longitudinal studies that include functional neuroimaging could assess functional activation before the onset of anxiety symptoms (or before trauma exposure in the case of PTSD) to determine whether baseline amygdala activation predicts (or increases the risk for) subsequent anxiety disorder diagnoses. One recent study using a variant of this longitudinal design has yielded findings suggesting that amygdala activation may represent a vulnerability factor. In this study, amygdala activation in response to novel faces was studied in adults who were categorized in childhood as either behaviorally inhibited or uninhibited (Schwartz et al, 2003). Behavioral inhibition in childhood is a known risk factor for the development of social anxiety later in life (Biederman et al, 2001; Schwartz et al, 1999). Amygdala activation was greater in the inhibited group as compared with the uninhibited group, and this finding remained even when inhibited subjects with social phobia were removed from the analyses. Although this study does not provide definitive proof that exaggerated amygdala activation is a vulnerability factor for the development of social phobia, it does lend some support to the idea.

The second type of study that can help determine whether functional abnormalities are acquired characteristics or vulnerability factors involves studying the identical twins of probands with $v s$ without the disorder in question. With regard to PTSD, Roger Pitman and colleagues have studied combat veterans with PTSD and their combat-unexposed identical co-twins without PTSD, as well as combat veterans who never had PTSD and their identical combat-unexposed co-twins without PTSD. Structural and functional abnormalities that are observed in both the individuals with PTSD and their identical trauma-unexposed co-twins likely represent familial vulnerability factors, whereas abnormalities that are observed only in the individuals with PTSD would be consistent with acquired characteristics. Using this type of design, diminished hippocampal volumes (Gilbertson et al, 2002) and dACC hypermetabolism (Shin et $a l$, in press) appear to be familial vulnerability factors, whereas diminished gray matter volumes in the rACC appear to be acquired characteristics (Kasai et al, 2008).

This twin design, however, is unable to determine whether familial vulnerability is attributable to genetic $v s$ environmental factors. Future studies will be needed to determine whether the functional abnormalities that appear to be familial vulnerability factors are associated with specific genotypes. For example, dACC hypermetabolism has been reported in healthy carriers of the short allele of the serotonin transporter polymorphism (Graff-Guerrero et al, 2005). The prevalence of the short allele appears to be elevated in PTSD (Lee et al, 2005), and the finding of dACC hypermetabolism in individuals with PTSD and their identical co-twins could be at least in part attributable to the presence of this short allele. Future studies will evaluate this possibility. Studies that examine links between specific genotypes and endophenotypes (eg, neuroimaging or neuroendocrine measures) that may predispose individuals to various anxiety disorders following environmental modulation (during development or in adulthood) are likely to prove very valuable in future research.

Much more progress is urgently needed in examining in vivo neurochemistry in anxiety disorders. SPECT, PET, and MRS studies are needed to link functional neuroimaging data with cellular and molecular changes that might be driving these abnormalities. Finally, another major future direction would entail using functional neuroimaging to predict treatment response in patients with anxiety disorders. This type of research has recently begun, and some studies have reported that greater amygdala activation at a pre-treatment baseline predicts a less favorable response to (1) cognitive-behavioral therapy in PTSD (Bryant et al, 2008a), and (2) venlafaxine in GAD (Whalen et al, 2008). Future studies will be needed to determine whether specific pre-treatment functional neuroimaging profiles can distinguish between those who will respond to medication $v s$ cognitive-behavioral treatments. One ultimate goal of this research would be to determine whether functional neuroimaging measures can be used to guide treatment choice for individual patients.

\section{ACKNOWLEDGEMENTS}

We thank Kathryn Handwerger for her comments on this article, and Anna Ogawa, Madhuri Ahluwalia, and Brittany Holiday for their research assistance.

\section{DISCLOSURE/CONFLICT OF INTEREST}

The authors have no conflicts or disclosures.

\section{REFERENCES}

Abelson JL, Khan S, Liberzon I, Erickson TM, Young EA (2008). Effects of perceived control and cognitive coping on endocrine stress responses to pharmacological activation. Biol Psychiatry 64: 701-707.

Abelson JL, Khan S, Liberzon I, Young EA (2007). HPA axis activity in patients with panic disorder: review and synthesis of four studies. Depress Anxiety 24: 66-76.

Abelson JL, Liberzon I, Young EA, Khan S (2005). Cognitive modulation of the endocrine stress response to a pharmacological challenge in normal and panic disorder subjects. Arch Gen Psychiatry 62: 668-675.

Albert CM, Chae CU, Rexrode KM, Manson JE, Kawachi I (2005). Phobic anxiety and risk of coronary heart disease and sudden cardiac death among women. Circulation 111: 480-487.

Alvarez RP, Biggs A, Chen G, Pine DS, Grillon C (2008). Contextual fear conditioning in humans: cortical-hippocampal and amygdala contributions. J Neurosci 28: 6211-6219.

Amaral DG (2002). The primate amygdala and the neurobiology of social behavior: implications for understanding social anxiety. Biol Psychiatry 51: 11-17.

Amir N, Klumpp H, Elias J, Bedwell JS, Yanasak N, Miller LS (2005). Increased activation of the anterior cingulate cortex during processing of disgust faces in individuals with social phobia. Biol Psychiatry 57: 975-981.

American Psychiatric Association (2000). Diagnostic and Statistical Manual of Mental Disorders, 4th edn. Text-Revision. American Psychiatric Press, Washington, DC.

Armony JL, Corbo V, Clement MH, Brunet A (2005). Amygdala response in patients with acute PTSD to masked and unmasked emotional facial expressions. Am J Psychiatry 162: 1961-1963.

Asami T, Hayano F, Nakamura M, Yamasue H, Uehara K, Otsuka T et al (2008). Anterior cingulate cortex volume reduction in patients with panic disorder. Psychiatry Clin Neurosci 62: 322-330. 
Astur RS, St Germain SA, Tolin D, Ford J, Russell D, Stevens M (2006). Hippocampus function predicts severity of post-traumatic stress disorder. Cyberpsychol Behav 9: 234-240. First study to use virtual reality and fMRI to study brain function in PTSD.

Atmaca M, Yildirim BH, Ozdemir BH, Aydin BA, Tezcan AE, Ozler AS (2006). Volumetric MRI assessment of brain regions in patients with refractory obsessivecompulsive disorder. Prog Neuropsychopharmacol Biol Psychiatry 30: 1051-1057.

Baran SE, Armstrong CE, Niren DC, Hanna JJ, Conrad CD (2009). Chronic stress and sex differences on the recall of fear conditioning and extinction. Neurobiol Learn Mem 91: 323-332.

Barrett J, Armony JL (2009). Influence of trait anxiety on brain activity during the acquisition and extinction of aversive conditioning. Psychol Med 39: 255-265

Bartha R, Stein MB, Williamson PC, Drost DJ, Neufeld RW, Carr TJ et al (1998). A short echo $1 \mathrm{H}$ spectroscopy and volumetric MRI study of the corpus striatum in patients with obsessive-compulsive disorder and comparison subjects. Am J Psychiatry 155: 1584-1591.

Baxter Jr LR, Phelps ME, Mazziotta JC, Guze BH, Schwartz JM, Selin CE (1987). Local cerebral glucose metabolic rates in obsessive-compulsive disorder. A comparison with rates in unipolar depression and in normal controls. Arch Gen Psychiatry 44: 211-218. One of the first positron emission tomographic studies of obsessive-compulsive disorder.

Baxter Jr LR, Schwartz JM, Mazziotta JC, Phelps ME, Pahl JJ, Guze BH et al (1988). Cerebral glucose metabolic rates in nondepressed patients with obsessive-compulsive disorder. Am J Psychiatry 145: 1560-1563.

Benkelfat C, Bradwejn J, Meyer E, Ellenbogen M, Milot S, Gjedde A et al (1995). Functional neuroanatomy of CCK4-induced anxiety in normal healthy volunteers. Am J Psychiatry 152: 1180-1184.

Biederman J, Hirshfeld-Becker DR, Rosenbaum JF, Herot C, Friedman D, Snidman $\mathrm{N}$ et al (2001). Further evidence of association between behavioral inhibition and social anxiety in children. Am J Psychiatry 158: 1673-1679.

Binder EB, Bradley RG, Liu W, Epstein MP, Deveau TC, Mercer KB et al (2008). Association of FKBP5 polymorphisms and childhood abuse with risk of posttraumatic stress disorder symptoms in adults. JAMA 299: 1291-1305.

Birbaumer N, Grodd W, Diedrich O, Klose U, Erb M, Lotze M et al (1998). fMRI reveals amygdala activation to human faces in social phobics. Neuroreport $\mathbf{9}$ : 1223-1226.

Bisaga A, Katz JL, Antonini A, Wright CE, Margouleff C, Gorman JM et al (1998). Cerebral glucose metabolism in women with panic disorder. Am J Psychiatry 155: 1178-1183.

Bishop S, Duncan J, Brett M, Lawrence AD (2004a). Prefrontal cortical function and anxiety: controlling attention to threat-related stimuli. Nat Neurosci 7: 184-188.

Bishop SJ, Duncan J, Lawrence AD (2004b). State anxiety modulation of the amygdala response to unattended threat-related stimuli. J Neurosci 24: 10364-10368.

Blair K, Geraci M, Devido J, McCaffrey D, Chen G, Vythilingam M et al (2008a). Neural response to self- and other referential praise and criticism in generalized social phobia. Arch Gen Psychiatry 65: 1176-1184.

Blair K, Shaywitz J, Smith BW, Rhodes R, Geraci M, Jones M et al (2008b). Response to emotional expressions in generalized social phobia and generalized anxiety disorder: evidence for separate disorders. Am J Psychiatry 165: 1193-1202.

Blechert J, Michael T, Vriends N, Margraf J, Wilhelm FH (2007). Fear conditioning in posttraumatic stress disorder: evidence for delayed extinction of autonomic, experiential, and behavioural responses. Behav Res Ther 45: 2019-2033.

Bonne O, Brandes D, Gillboa A, Gomori JM, Shenton ME, Pitman RK et al (2001). Longitudinal MRI study of hippocampal volume in trauma survivors with PTSD. Am J Psychiatry 158: 1248-1251.

Boshuisen ML, Ter Horst GJ, Paans AM, Reinders AA, den Boer JA (2002). rCBF differences between panic disorder patients and control subjects during anticipatory anxiety and rest. Biol Psychiatry 52: 126-135.

Bossini L, Tavanti M, Calossi S, Lombardelli A, Polizzotto NR, Galli R et al (2008). Magnetic resonance imaging volumes of the hippocampus in drug-naive patients with post-traumatic stress disorder without comorbidity conditions. J Psychiatr Res 42: 752-762.

Bossini L, Tavanti M, Lombardelli A, Calossi S, Polizzotto NR, Galli R et al (2007). Changes in hippocampal volume in patients with post-traumatic stress disorder after sertraline treatment. J Clin Psychopharmacol 27: 233-235.

Bouton ME, Westbrook RF, Corcoran KA, Maren S (2006). Contextual and temporal modulation of extinction: behavioral and biological mechanisms. Biol Psychiatry 60: $352-360$

Breiter HC, Etcoff NL, Whalen PJ, Kennedy WA, Rauch SL, Buckner RL et al (1996a). Response and habituation of the human amygdala during visual processing of facial expression. Neuron 17: 875-887. One of two initial fMRI studies to demonstrate amygdala responses to facial expressions.

Breiter HC, Rauch SL, Kwong KK, Baker JR, Weisskoff RM, Kennedy DN et al (1996b). Functional magnetic resonance imaging of symptom provocation in obsessive-compulsive disorder. Arch Gen Psychiatry 53: 595-606.

Bremner JD, Innis RB, Southwick SM, Staib L, Zoghbi S, Charney DS (2000a). Decreased benzodiazepine receptor binding in prefrontal cortex in combatrelated posttraumatic stress disorder. Am J Psychiatry 157: 1120-1126.

Bremner JD, Innis RB, White T, Fujita M, Silbersweig D, Goddard AW et al (2000b). SPECT [l-123]iomazenil measurement of the benzodiazepine receptor in panic disorder. Biol Psychiatry 47: 96-106.

Bremner JD, Narayan M, Staib LH, Southwick SM, McGlashan T, Charney DS (1999a). Neural correlates of memories of childhood sexual abuse in women with and without posttraumatic stress disorder. Am J Psychiatry 156: 1787-1795.

Bremner JD, Randall P, Scott TM, Bronen RA, Seibyl JP, Southwick SM et al (1995). MRI-based measurement of hippocampal volume in patients with combatrelated posttraumatic stress disorder. Am J Psychiatry 152: 973-981. The first demonstration of diminished hippocampal volumes in PTSD.

Bremner JD, Randall P, Vermetten E, Staib L, Bronen RA, Mazure C et al (1997). Magnetic resonance imaging-based measurement of hippocampal volume in posttraumatic stress disorder related to childhood physical and sexual abusea preliminary report. Biol Psychiatry 41: 23-32.

Bremner JD, Staib LH, Kaloupek D, Southwick SM, Soufer R, Charney DS (1999b). Neural correlates of exposure to traumatic pictures and sound in Vietnam combat veterans with and without posttraumatic stress disorder: a positron emission tomography study. Biol Psychiatry 45: 806-816.

Bremner JD, Vermetten E, Schmahl C, Vaccarino V, Vythilingam M, Afzal N et al (2005). Positron emission tomographic imaging of neural correlates of a fear acquisition and extinction paradigm in women with childhood sexual-abuserelated post-traumatic stress disorder. Psychol Med 35: 791-806.

Bremner JD, Vermetten E, Vythilingam M, Afzal N, Schmahl C, Elzinga B et al (2004). Neural correlates of the classic color and emotional stroop in women with abuse-related posttraumatic stress disorder. Biol Psychiatry 55: 612-620.

Bremner JD, Vythilingam M, Vermetten E, Southwick SM, McGlashan T, Nazeer A et al (2003a). MRI and PET study of deficits in hippocampal structure and function in women with childhood sexual abuse and posttraumatic stress disorder. Am J Psychiatry 160: 924-932.

Bremner JD, Vythilingam M, Vermetten E, Southwick SM, McGlashan T, Staib LH et al (2003b). Neural correlates of declarative memory for emotionally valenced words in women with posttraumatic stress disorder related to early childhood sexual abuse. Biol Psychiatry 53: 879-889

Britton JC, Gold AL, Deckersbach T, Rauch SL (2009). Functional MRI study of specific animal phobia using an event-related emotional counting stroop paradigm. Depress Anxiety (in press).

Britton JC, Phan KL, Taylor SF, Fig LM, Liberzon I (2005). Corticolimbic blood flow in posttraumatic stress disorder during script-driven imagery. Biol Psychiatry 57: 832-840.

Britton JC, Phan KL, Taylor SF, Welsh RC, Berridge KC, Liberzon I (2006). Neural correlates of social and nonsocial emotions: an fMRI study. Neuroimage 31: 397-409.

Brown S, Freeman T, Kimbrell T, Cardwell D, Komoroski R (2003). In vivo proton magnetic resonance spectroscopy of the medial temporal lobes of former prisoners of war with and without posttraumatic stress disorder. J Neuropsychiatry Clin Neurosci 15: 367-370.

Bryant RA, Felmingham K, Kemp A, Das P, Hughes G, Peduto A et al (2008a). Amygdala and ventral anterior cingulate activation predicts treatment response to cognitive behaviour therapy for post-traumatic stress disorder. Psychol Med 38: 555-561. An important study that demonstrates a relationship between pre-treatment $\mathrm{fMRI}$ measures and clinical improvement.

Bryant RA, Felmingham KL, Kemp AH, Barton M, Peduto AS, Rennie $\mathrm{C}$ et al (2005). Neural networks of information processing in posttraumatic stress disorder: a functional magnetic resonance imaging study. Biol Psychiatry 58: 111-118.

Bryant RA, Kemp AH, Felmingham KL, Liddell B, Olivieri G, Peduto A et al (2008b). Enhanced amygdala and medial prefrontal activation during nonconscious processing of fear in posttraumatic stress disorder: An fMRI study. Hum Brain Mapp 29: 517-523.

Buchel C, Dolan RJ, Armony JL, Friston KJ (1999). Amygdala-hippocampal involvement in human aversive trace conditioning revealed through event-related functional magnetic resonance imaging. J Neurosci 19: 10869-10876.

Buchel C, Morris J, Dolan RJ, Friston KJ (1998). Brain systems mediating aversive conditioning: an event-related fMRI study. Neuron 20: 947-957. 
Bystritsky A, Pontillo D, Powers M, Sabb FW, Craske MG, Bookheimer SY (2001). Functional MRI changes during panic anticipation and imagery exposure. Neuroreport 12: 3953-3957.

Cahill L, Haier RJ, Fallon J, Alkire MT, Tang C, Keator D et al (1996). Amygdala activity at encoding correlated with long-term, free recall of emotional information. Proc Natl Acad Sci USA 93: 8016-8021. One of the first studies to associate amygdala activity during the encoding of emotional material with its subsequent recollection.

Caldji C, Francis D, Sharma S, Plotsky PM, Meaney MJ (2000). The effects of early rearing environment on the development of GABAA and central benzodiazepine receptor levels and novelty-induced fearfulness in the rat. Neuropsychopharmacology 22: 219-229.

Cameron OG, Zubieta JK, Grunhaus L, Minoshima S (2000). Effects of yohimbine on cerebral blood flow, symptoms, and physiological functions in humans. Psychosom Med 62: 549-559.

Campbell DW, Sareen J, Paulus MP, Goldin PR, Stein MB, Reiss JP (2007). Timevarying amygdala response to emotional faces in generalized social phobia. Biol Psychiatry 62: 455-463.

Cannistraro PA, Wright Cl, Wedig MM, Martis B, Shin LM, Wilhelm S et al (2004). Amygdala responses to human faces in obsessive-compulsive disorder. Biol Psychiatry 56: 916-920.

Carrion VG, Garrett A, Menon V, Weems CF, Reiss AL (2008). Posttraumatic stress symptoms and brain function during a response-inhibition task: an $\mathrm{fMRI}$ study in youth. Depress Anxiety 25: 514-526.

Carrion VG, Weems CF, Eliez S, Patwardhan A, Brown W, Ray RD et al (2001). Attenuation of frontal asymmetry in pediatric posttraumatic stress disorder. Biol Psychiatry 50: 943-951.

Chamberlain SR, Menzies L, Hampshire A, Suckling J, Fineberg NA, del Campo N et al (2008). Orbitofrontal dysfunction in patients with obsessive-compulsive disorder and their unaffected relatives. Science 321: 421-422.

Chen S, Xia W, Li L, Liu J, He Z, Zhang Z et al (2006). Gray matter density reduction in the insula in fire survivors with posttraumatic stress disorder: a voxel-based morphometric study. Psychiatry Res 146: 65-72.

Chen XL, Xie JX, Han HB, Cui YH, Zhang BQ (2004). MR perfusion-weighted imaging and quantitative analysis of cerebral hemodynamics with symptom provocation in unmedicated patients with obsessive-compulsive disorder. Neurosci Lett 370: 206-211.

Cheng DT, Knight DC, Smith CN, Helmstetter FJ (2006). Human amygdala activity during the expression of fear responses. Behav Neurosci 120: 1187-1195.

Cheng DT, Knight DC, Smith CN, Stein EA, Helmstetter FJ (2003). Functional MRI of human amygdala activity during Pavlovian fear conditioning: stimulus processing vs response expression. Behav Neurosci 117: 3-10.

Chung YA, Kim SH, Chung SK, Chae JH, Yang DW, Sohn HS et al (2006). Alterations in cerebral perfusion in posttraumatic stress disorder patients without re-exposure to accident-related stimuli. Clin Neurophysiol 117: 637-642.

Cooney RE, Atlas LY, Joormann J, Eugene F, Gotlib IH (2006). Amygdala activation in the processing of neutral faces in social anxiety disorder: is neutral really neutral? Psychiatry Res 148: 55-59.

Coplan JD, Andrews MW, Rosenblum LA, Owens MJ, Friedman S, Gorman JM et al (1996). Persistent elevations of cerebrospinal fluid concentrations of corticotropin-releasing factor in adult nonhuman primates exposed to early-life stressors: implications for the pathophysiology of mood and anxiety disorders. Proc Natl Acad Sci USA 93: 1619-1623.

Coplan JD, Lydiard RB (1998). Brain circuits in panic disorder. Biol Psychiatry 44 1264-1276.

Corbo V, Clement MH, Armony JL, Pruessner JC, Brunet A (2005). Size vs shape differences: contrasting voxel-based and volumetric analyses of the anterior cingulate cortex in individuals with acute posttraumatic stress disorder. Biol Psychiatry 58: 119-124. Demonstrates that voxel-based morphometric measures are not always consistent with more traditional segmentation volumetric measures.

Cordero MI, Venero C, Kruyt ND, Sandi C (2003). Prior exposure to a single stress session facilitates subsequent contextual fear conditioning in rats. Evidence for a role of corticosterone. Horm Behav 44: 338-345.

Critchley HD, Mathias CJ, Dolan RJ (2002). Fear conditioning in humans: the influence of awareness and autonomic arousal on functional neuroanatomy. Neuron 33: 653-663.

Curtis G, Buxton M, Lippman D, Nesse R, Wright J (1976). 'Flooding in vivo' during the circadian phase of minimal cortisol secretion: anxiety and therapeutic success without adrenal cortical activation. Biol Psychiatry 11: 101-107.

Davis M (2006). Neural systems involved in fear and anxiety measured with fearpotentiated startle. Am Psychol 61: 741-756.

Davis M, Whalen PJ (2001). The amygdala: vigilance and emotion. Mol Psychiatry 6: 13-34. An excellent review of studies of amygdala function in human and non-human animals
De Bellis MD, Casey BJ, Dahl RE, Birmaher B, Williamson DE, Thomas KM et al (2000a). A pilot study of amygdala volumes in pediatric generalized anxiety disorder. Biol Psychiatry 48: 51-57.

De Bellis MD, Hall J, Boring AM, Frustaci K, Moritz G (2001a). A pilot longitudinal study of hippocampal volumes in pediatric maltreatment-related posttraumatic stress disorder. Biol Psychiatry 50: 305-309.

De Bellis MD, Keshavan MS, Clark DB, Casey BJ, Giedd JN, Boring AM et al (1999). A.E. Bennett research award. Developmental traumatology. Part II: Brain development. Biol Psychiatry 45: 1271-1284.

De Bellis MD, Keshavan MS, Harenski KA (2001b). Anterior cingulate $\mathrm{N}$-acetylaspartate/creatine ratios during clonidine treatment in a maltreated child with posttraumatic stress disorder. J Child Adolesc Psychopharmacol 11: 311-316.

De Bellis MD, Keshavan MS, Shifflett H, lyengar S, Beers SR, Hall J et al (2002). Brain structures in pediatric maltreatment-related posttraumatic stress disorder: a sociodemographically matched study. Biol Psychiatry 52: 1066-1078.

De Bellis MD, Keshavan MS, Spencer S, Hall J (2000b). N-Acetylaspartate concentration in the anterior cingulate of maltreated children and adolescents with PTSD. Am J Psychiatry 157: 1175-1177.

De Cristofaro MT, Sessarego A, Pupi A, Biondi F, Faravelli C (1993). Brain perfusion abnormalities in drug-naive, lactate-sensitive panic patients: a SPECT study. Biol Psychiatry 33: 505-512.

Dickie EW, Brunet A, Akerib V, Armony JL (2008). An fMRI investigation of memory encoding in PTSD: influence of symptom severity. Neuropsychologia 46: 1522-1531.

Dilger S, Straube T, Mentzel HJ, Fitzek C, Reichenbach JR, Hecht H et al (2003). Brain activation to phobia-related pictures in spider phobic humans: an eventrelated functional magnetic resonance imaging study. Neurosci Lett 348: 29-32.

Dolcos F, LaBar KS, Cabeza R (2004). Interaction between the amygdala and the medial temporal lobe memory system predicts better memory for emotional events. Neuron 42: 855-863.

Dolcos F, LaBar KS, Cabeza R (2005). Remembering one year later: role of the amygdala and the medial temporal lobe memory system in retrieving emotional memories. Proc Natl Acad Sci USA 102: 2626-2631.

Domschke K, Braun M, Ohrmann P, Suslow T, Kugel H, Bauer J et al (2006). Association of the functional [minus sign]1019C/G 5-HT 1A polymorphism with prefrontal cortex and amygdala activation measured with $3 \mathrm{~T} \mathrm{fMRl}$ in panic disorder. Int J Neuropsychopharmacol 9: 349-355.

Domschke K, Ohrmann P, Braun M, Suslow T, Bauer J, Hohoff C et al (2008). Influence of the catechol-O-methyltransferase val158met genotype on amygdala and prefrontal cortex emotional processing in panic disorder. Psychiatry Res 163: 13-20.

Doronbekov TK, Tokunaga H, Ikejiri Y, Kazui H, Hatta N, Masaki $Y$ et al (2005). Neural basis of fear conditioning induced by video clip: positron emission tomography study. Psychiatry Clin Neurosci 59: 155-162.

Driessen M, Beblo T, Mertens M, Piefke M, Rullkoetter N, Silva-Saavedra A et al (2004). Posttraumatic stress disorder and fMRI activation patterns of traumatic memory in patients with borderline personality disorder. Biol Psychiatry 55: 603-611.

Dunsmoor JE, Bandettini PA, Knight DC (2007). Impact of continuous vs intermittent CS-UCS pairing on human brain activation during Pavlovian fear conditioning. Behav Neurosci 121: 635-642.

Ebert D, Speck O, Konig A, Berger M, Hennig J, Hohagen F (1997). 1H-magnetic resonance spectroscopy in obsessive-compulsive disorder: evidence for neuronal loss in the cingulate gyrus and the right striatum. Psychiatry Res 74: 173-176.

Elzinga BM, Bremner JD (2002). Are the neural substrates of memory the final common pathway in posttraumatic stress disorder (PTSD)? J Affect Disord 70 $1-17$.

Eser D, Leicht G, Lutz J, Wenninger S, Kirsch V, Schule C et al (2009). Functional neuroanatomy of CCK-4-induced panic attacks in healthy volunteers. Hum Brain Мapp 30: 511-522

Etkin A, Wager TD (2007). Functional neuroimaging of anxiety: a meta-analysis of emotional processing in PTSD, social anxiety disorder, and specific phobia Am J Psychiatry 164: 1476-1488. A thorough and novel review of functional neuroimaging studies of anxiety disorders.

Evans KC, Simon NM, Dougherty DD, Hoge EA, Worthington JJ, Chow C et al (2009). A PET study of tiagabine treatment implicates ventral medial prefrontal cortex in generalized social anxiety disorder. Neuropsychopharmacology 34: 390-398.

Evans KC, Wright Cl, Wedig MM, Gold AL, Pollack MH, Rauch SL (2008). A functional MRI study of amygdala responses to angry schematic faces in social anxiety disorder. Depress Anxiety 25: 496-505.

Falsetti SA, Resnick HS (1997). Frequency and severity of panic attack symptoms in a treatment seeking sample of trauma victims. J Trauma Stress 10: 683-689. 
Felmingham K, Kemp A, Williams L, Das P, Hughes G, Peduto A et al (2007). Changes in anterior cingulate and amygdala after cognitive behavior therapy of posttraumatic stress disorder. Psychol Sci 18: 127-129.

Felmingham KL, Williams LM, Kemp AH, Rennie C, Gordon E, Bryant RA (2009). Anterior cingulate activity to salient stimuli is modulated by autonomic arousal in Posttraumatic Stress Disorder. Psychiatry Res: Neuroimaging 173: 59-62.

Fennema-Notestine C, Stein MB, Kennedy CM, Archibald SL, Jernigan TL (2002). Brain morphometry in female victims of intimate partner violence with and without posttraumatic stress disorder. Biol Psychiatry 52: 1089-1101.

Fitzgerald DA, Angstadt M, Jelsone LM, Nathan PJ, Phan KL (2006). Beyond threat: amygdala reactivity across multiple expressions of facial affect. Neuroimage 30: 1441-1448.

Fitzgerald KD, Moore GJ, Paulson LA, Stewart CM, Rosenberg DR (2000). Proton spectroscopic imaging of the thalamus in treatment-naive pediatric obsessivecompulsive disorder. Biol Psychiatry 47: 174-182.

Fitzgerald KD, Welsh RC, Gehring WJ, Abelson JL, Himle JA, Liberzon I et al (2005). Error-related hyperactivity of the anterior cingulate cortex in obsessivecompulsive disorder. Biol Psychiatry 57: 287-294.

Frances A, Widiger T, Fyer MR (1990). The influence of classification methods on comorbidity. In: Maser J, Cloninger R (eds). Comorbidity of Mood and Anxiety Disorders. American Psychiatric Press, Washington, DC

Freeman TW, Cardwell D, Karson CN, Komoroski RA (1998). In vivo proton magnetic resonance spectroscopy of the medial temporal lobes of subjects with combat-related posttraumatic stress disorder. Magn Reson Med 40: 66-71.

Friedlander L, Desrocher M (2006). Neuroimaging studies of obsessive-compulsive disorder in adults and children. Clin Psychol Rev 26: 32-49.

Fujita M, Southwick SM, Denucci CC, Zoghbi SS, Dillon MS, Baldwin RM et al (2004). Central type benzodiazepine receptors in Gulf War veterans with posttraumatic stress disorder. Biol Psychiatry 56: 95-100.

Furmark T, Appel L, Michelgard A, Wahlstedt K, Ahs F, Zancan S et al (2005). Cerebral blood flow changes after treatment of social phobia with the neurokinin1 antagonist GR205171, citalopram, or placebo. Biol Psychiatry 58: 132-142.

Furmark T, Fischer H, Wik G, Larsson M, Fredrikson M (1997). The amygdala and individual differences in human fear conditioning. Neuroreport 8: 3957-3960.

Furmark T, Tillfors M, Garpenstrand H, Marteinsdottir I, Langstrom B, Oreland L et al (2004). Serotonin transporter polymorphism related to amygdala excitability and symptom severity in patients with social phobia. Neurosci Lett 362: 189-192.

Furmark T, Tillfors M, Marteinsdottir I, Fischer H, Pissiota A, Langstrom B et al (2002). Common changes in cerebral blood flow in patients with social phobia treated with citalopram or cognitive-behavioral therapy. Arch Gen Psychiatry 59: 425-433

Fyer AJ (1998). Current approaches to etiology and pathophysiology of specific phobia. Biol Psychiatry 44: 1295-1304.

Garavan H, Pendergrass JC, Ross TJ, Stein EA, Risinger RC (2001). Amygdala response to both positively and negatively valenced stimuli. Neuroreport 12: 2779-2783.

Garcia R, Vouimba RM, Baudry M, Thompson RF (1999). The amygdala modulates prefrontal cortex activity relative to conditioned fear. Nature 402: 294-296. An important study suggesting that the amygdala can attenuate medial prefrontal cortex function.

Gentili C, Gobbini MI, Ricciardi E, Vanello N, Pietrini P, Haxby JV et al (2008). Differential modulation of neural activity throughout the distributed neural system for face perception in patients with social phobia and healthy subjects. Brain Res Bull 77: 286-292.

Geuze E, van Berckel BN, Lammertsma AA, Boellaard R, de Kloet CS, Vermetten E et al (2008a). Reduced GABAA benzodiazepine receptor binding in veterans with post-traumatic stress disorder. Mol Psychiatry 13: 74-83, 73.

Geuze E, Vermetten E, Ruf M, de Kloet CS, Westenberg HG (2008b). Neural correlates of associative learning and memory in veterans with posttraumatic stress disorder. J Psychiatr Res 42: 659-669.

Geuze E, Westenberg HG, Jochims A, de Kloet CS, Bohus M, Vermetten E et al (2007). Altered pain processing in veterans with posttraumatic stress disorder. Arch Gen Psychiatry 64: 76-85.

Gilbert AR, Moore GJ, Keshavan MS, Paulson LA, Narula V, Mac Master FP et al (2000). Decrease in thalamic volumes of pediatric patients with obsessivecompulsive disorder who are taking paroxetine. Arch Gen Psychiatry 57: 449-456.

Gilbertson MW, Shenton ME, Ciszewski A, Kasai K, Lasko NB, Orr SP et al (2002). Smaller hippocampal volume predicts pathologic vulnerability to psychological trauma. Nat Neurosci 5: 1242-1247.

Golier JA, Yehuda R, De Santi S, Segal S, Dolan S, de Leon MJ (2005). Absence of hippocampal volume differences in survivors of the Nazi holocaust with and without posttraumatic stress disorder. Psychiatry Res 139: 53-64.

Goossens L, Schruers K, Peeters R, Griez E, Sunaert S (2007a). Visual presentation of phobic stimuli: amygdala activation via an extrageniculostriate pathway? Psychiatry Res 155: 113-120.
Goossens L, Sunaert S, Peeters R, Griez EJ, Schruers KR (2007b). Amygdala hyperfunction in phobic fear normalizes after exposure. Biol Psychiatry 62: 1119-1125.

Gorman JM, Kent JM, Sullivan GM, Coplan JD (2000). Neuroanatomical hypothesis of panic disorder, revised. Am J Psychiatry 157: 493-505. An influential neurobiological account of panic attacks and panic disorder.

Gorno-Tempini ML, Pradelli S, Serafini M, Pagnoni G, Baraldi P, Porro C et al (2001). Explicit and incidental facial expression processing: an fMRI study. Neuroimage 14: $465-473$.

Gottfried JA, Dolan RJ (2004). Human orbitofrontal cortex mediates extinction learning while accessing conditioned representations of value. Nat Neurosci 7: 1144-1152.

Graff-Guerrero A, De la Fuente-Sandoval C, Camarena B, Gomez-Martin D, Apiquian R, Fresan A et al (2005). Frontal and limbic metabolic differences in subjects selected according to genetic variation of the SLC6A4 gene polymorphism. Neuroimage 25: 1197-1204.

Graybiel AM, Rauch SL (2000). Toward a neurobiology of obsessive-compulsive disorder. Neuron 28: 343-347.

Greenberg PE, Sisitsky T, Kessler RC, Finkelstein SN, Berndt ER, Davidson JR et al (1999). The economic burden of anxiety disorders in the 1990s. J Clin Psychiatry 60: 427-435.

Grillon C, Duncko R, Covington MF, Kopperman L, Kling MA (2007). Acute stress potentiates anxiety in humans. Biol Psychiatry 62: 1183-1186.

Gurvits TV, Shenton ME, Hokama H, Ohta H, Lasko NB, Gilbertson MW et al (1996). Magnetic resonance imaging study of hippocampal volume in chronic, combatrelated posttraumatic stress disorder. Biol Psychiatry 40: 1091-1099.

Guyer AE, Lau JY, McClure-Tone EB, Parrish J, Shiffrin ND, Reynolds RC et al (2008). Amygdala and ventrolateral prefrontal cortex function during anticipated peer evaluation in pediatric social anxiety. Arch Gen Psychiatry 65: 1303-1312.

Ham BJ, Chey J, Yoon SJ, Sung Y, Jeong DU, Ju Kim S et al (2007a). Decreased $\mathrm{N}$-acetyl-aspartate levels in anterior cingulate and hippocampus in subjects with post-traumatic stress disorder: a proton magnetic resonance spectroscopy study. Eur J Neurosci 25: 324-329.

Ham BJ, Sung Y, Kim N, Kim SJ, Kim JE, Kim DJ et al (2007b). Decreased GABA levels in anterior cingulate and basal ganglia in medicated subjects with panic disorder: a proton magnetic resonance spectroscopy (1H-MRS) study. Prog Neuropsychopharmacol Biol Psychiatry 31: 403-411.

Hamann S, Mao H (2002). Positive and negative emotional verbal stimuli elicit activity in the left amygdala. Neuroreport 13: 15-19.

Hamann SB, Ely TD, Grafton ST, Kilts CD (1999). Amygdala activity related to enhanced memory for pleasant and aversive stimuli. Nat Neurosci 2: 289-293.

Hamann SB, Ely TD, Hoffman JM, Kilts CD (2002). Ecstasy and agony: activation of the human amygdala in positive and negative emotion. Psychol Sci 13: 135-141.

Hamner MB, Lorberbaum JP, George MS (1999). Potential role of the anterior cingulate cortex in PTSD: review and hypothesis. Depress Anxiety 9: 1-14.

Han DH, Renshaw PF, Dager SR, Chung A, Hwang J, Daniels MA et al (2008). Altered cingulate white matter connectivity in panic disorder patients. J Psychiatr Res 42: 399-407.

Hariri AR, Tessitore A, Mattay VS, Fera F, Weinberger DR (2002). The amygdala response to emotional stimuli: a comparison of faces and scenes. Neuroimage 17: 317-323.

Harmer CJ, Mackay CE, Reid CB, Cowen PJ, Goodwin GM (2006). Antidepressant drug treatment modifies the neural processing of nonconscious threat cues. Biol Psychiatry 59: 816-820. Demonstrates that antidepressant medication diminishes amygdala responses during functional neuroimaging

Hasler G, Nugent AC, Carlson PJ, Carson RE, Geraci M, Drevets WC (2008). Altered cerebral gamma-aminobutyric acid type A-benzodiazepine receptor binding in panic disorder determined by [11C]flumazenil positron emission tomography. Arch Gen Psychiatry 65: 1166-1175.

Heim C, Nemeroff CB (2001). The role of childhood trauma in the neurobiology of mood and anxiety disorders: preclinical and clinical studies. Biol Psychiatry 49: 1023-1039.

Hendler T, Rotshtein P, Yeshurun Y, Weizmann T, Kahn I, Ben-Bashat D et al (2003). Sensing the invisible: differential sensitivity of visual cortex and amygdala to traumatic context. Neuroimage 19: 587-600.

Hermann A, Schafer A, Walter B, Stark R, Vaitl D, Schienle A (2007). Diminished medial prefrontal cortex activity in blood-injection-injury phobia. Biol Psychol 75: 124-130.

Hoehn-Saric R, Schlund MW, Wong SH (2004). Effects of citalopram on worry and brain activation in patients with generalized anxiety disorder. Psychiatry Res 131: 11-21.

Hopper JW, Frewen PA, van der Kolk BA, Lanius RA (2007). Neural correlates of reexperiencing, avoidance, and dissociation in PTSD: symptom dimensions and emotion dysregulation in responses to script-driven trauma imagery. J Trauma Stress 20: 713-725. 
Hou C, Liu J, Wang K, Li L, Liang M, He Z et al (2007). Brain responses to symptom provocation and trauma-related short-term memory recall in coal mining accident survivors with acute severe PTSD. Brain Res 1144: 165-174.

Irwin W, Davidson RJ, Lowe MJ, Mock BJ, Sorenson JA, Turski PA (1996). Human amygdala activation detected with echo-planar functional magnetic resonance imaging. Neuroreport 7: 1765-1769. One of the first fMRI studies to assess amygdala responses to emotional stimuli.

Jackson ED, Payne JD, Nadel L, Jacobs WJ (2006). Stress differentially modulates fear conditioning in healthy men and women. Biol Psychiatry 59: 516-522.

Javanmard M, Shlik J, Kennedy SH, Vaccarino FJ, Houle S, Bradwejn J (1999). Neuroanatomic correlates of CCK-4-induced panic attacks in healthy humans: a comparison of two time points. Biol Psychiatry 45: 872-882.

Kalisch R, Korenfeld E, Stephan KE, Weiskopf N, Seymour B, Dolan RJ (2006). Context-dependent human extinction memory is mediated by a ventromedial prefrontal and hippocampal network. J Neurosci 26: 9503-9511.

Kang DH, Kim JJ, Choi JS, Kim YI, Kim CW, Youn T et al (2004). Volumetric investigation of the frontal-subcortical circuitry in patients with obsessivecompulsive disorder. J Neuropsychiatry Clin Neurosci 16: 342-349.

Karl A, Schaefer M, Malta LS, Dorfel D, Rohleder N, Werner A (2006). A metaanalysis of structural brain abnormalities in PTSD. Neurosci Biobehav Rev 30: 1004-1031.

Kasai K, Yamasue H, Gilbertson MW, Shenton ME, Rauch SL, Pitman RK (2008). Evidence for acquired pregenual anterior cingulate gray matter loss from a twin study of combat-related posttraumatic stress disorder. Biol Psychiatry 63 550-556.

Kaschka W, Feistel H, Ebert D (1995). Reduced benzodiazepine receptor binding in panic disorders measured by iomazenil SPECT. J Psychiatr Res 29: 427-434.

Kawachi I, Colditz GA, Ascherio A, Rimm EB, Giovannucci E, Stampfer MJ et al (1994). Prospective study of phobic anxiety and risk of coronary heart disease in men. Circulation 89: 1992-1997.

Kelley WM, Macrae CN, Wyland CL, Caglar S, Inati S, Heatherton TF (2002). Finding the self? An event-related fMRI study. J Cogn Neurosci 14: 785-794.

Kemp AH, Felmingham K, Das P, Hughes G, Peduto AS, Bryant RA et al (2007). Influence of comorbid depression on fear in posttraumatic stress disorder: an fMRI study. Psychiatry Res 155: 265-269.

Kessler RC, Berglund P, Demler O, Jin R, Merikangas KR, Walters EE (2005). Lifetime prevalence and age-of-onset distributions of DSM-IV disorders in the National Comorbidity Survey Replication. Arch Gen Psychiatry 62: 593-602.

Ketter TA, Andreason PJ, George MS, Lee C, Gill DS, Parekh PI et al (1996). Anterior paralimbic mediation of procaine-induced emotional and psychosensory experiences. Arch Gen Psychiatry 53: 59-69.

Kilts CD, Kelsey JE, Knight B, Ely TD, Bowman FD, Gross RE et al (2006). The neural correlates of social anxiety disorder and response to pharmacotherapy. Neuropsychopharmacology 31: 2243-2253.

Kim H, Somerville LH, Johnstone T, Alexander AL, Whalen PJ (2003). Inverse amygdala and medial prefrontal cortex responses to surprised faces. Neuroreport 14: 2317-2322.

Kim H, Somerville LH, Johnstone T, Polis S, Alexander AL, Shin LM et al (2004). Contextual modulation of amygdala responsivity to surprised faces. J Cogn Neurosci 16: 1730-1745.

Kim MJ, Chey J, Chung A, Bae S, Khang H, Ham B et al (2007). Diminished rostral anterior cingulate activity in response to threat-related events in posttraumatic stress disorder. J Psychiatr Res 42: 268-277.

Kitayama N, Vaccarino V, Kutner M, Weiss P, Bremner JD (2005). Magnetic resonance imaging (MRI) measurement of hippocampal volume in posttraumatic stress disorder: a meta-analysis. J Affect Disord 88: 79-86.

Klucken T, Kagerer S, Schweckendiek J, Tabbert K, Vaitl D, Stark R (2009). Neural, electrodermal and behavioral response patterns in contingency aware and unaware subjects during a picture-picture conditioning paradigm. Neuroscience 158: $721-731$

Knight DC, Nguyen HT, Bandettini PA (2005). The role of the human amygdala in the production of conditioned fear responses. Neuroimage 26: 1193-1200.

Knight DC, Smith CN, Cheng DT, Stein EA, Helmstetter FJ (2004). Amygdala and hippocampal activity during acquisition and extinction of human fear conditioning. Cogn Affect Behav Neurosci 4: 317-325.

Knight DC, Waters NS, Bandettini PA (2009). Neural substrates of explicit and implicit fear memory. Neuroimage 45: 208-214.

Koenigs M, Huey ED, Raymont V, Cheon B, Solomon J, Wassermann EM et al (2008). Focal brain damage protects against post-traumatic stress disorder in combat veterans. Nat Neurosci 11: 232-237. Unique lesion study demonstrating the importance of the amygdala and medial prefrontal cortex in the pathophysiology of PTSD.

Krain AL, Gotimer K, Hefton S, Ernst M, Castellanos FX, Pine DS et al (2008). A functional magnetic resonance imaging investigation of uncertainty in adolescents with anxiety disorders. Biol Psychiatry 63: 563-568.
LaBar KS, Gatenby JC, Gore JC, LeDoux JE, Phelps EA (1998). Human amygdala activation during conditioned fear acquisition and extinction: a mixed-trial fMRI study. Neuron 20: 937-945.

Lane RD, Fink GR, Chau PM, Dolan RJ (1997a). Neural activation during selective attention to subjective emotional responses. Neuroreport 8: 3969-3972.

Lane RD, Reiman EM, Ahern GL, Schwartz GE, Davidson RJ (1997b). Neuroanatomical correlates of happiness, sadness, and disgust. Am J Psychiatry 154 926-933.

Lang S, Kroll A, Lipinski SJ, Wessa M, Ridder S, Christmann C et al (2009). Context conditioning and extinction in humans: differential contribution of the hippocampus, amygdala and prefrontal cortex. Eur J Neurosci 29: 823-832.

Lanius RA, Frewen PA, Girotti M, Neufeld RW, Stevens TK, Densmore M (2007). Neural correlates of trauma script-imagery in posttraumatic stress disorder with and without comorbid major depression: a functional MRI investigation. Psychiatry Res 155: 45-56.

Lanius RA, Williamson PC, Densmore M, Boksman K, Gupta MA, Neufeld RW et al (2001). Neural correlates of traumatic memories in posttraumatic stress disorder: a functional MRI investigation. Am J Psychiatry 158: 1920-1922. First in a series of unique 4 Tesla fMRI studies of PTSD using script-driven imagery.

Lanius RA, Williamson PC, Hopper J, Densmore M, Boksman K, Gupta MA et al (2003). Recall of emotional states in posttraumatic stress disorder: an fMRI investigation. Biol Psychiatry 53: 204-210.

Lansing K, Amen DG, Hanks C, Rudy L (2005). High-resolution brain SPECT imaging and eye movement desensitization and reprocessing in police officers with PTSD. J Neuropsychiatry Clin Neurosci 17: 526-532.

Lanzenberger RR, Mitterhauser M, Spindelegger C, Wadsak W, Klein N, Mien LK et al (2007). Reduced serotonin-1A receptor binding in social anxiety disorder. Biol Psychiatry 61: 1081-1089.

Larson CL, Schaefer HS, Siegle GJ, Jackson CA, Anderle MJ, Davidson RJ (2006). Fear is fast in phobic individuals: amygdala activation in response to fear-relevant stimuli. Biol Psychiatry 60: 410-417.

Layton B, Krikorian R (2002). Memory mechanisms in posttraumatic stress disorder. J Neuropsychiatry Clin Neurosci 14: 254-261.

LeDoux JE (2000). Emotion circuits in the brain. Annu Rev Neurosci 23: 155-184.

LeDoux JE, Cicchetti P, Xagoraris A, Romanski LM (1990). The lateral amygdaloid nucleus: sensory interface of the amygdala in fear conditioning. J Neurosci 10: 1062-1069.

Lee HJ, Lee MS, Kang RH, Kim H, Kim SD, Kee BS et al (2005). Influence of the serotonin transporter promoter gene polymorphism on susceptibility to posttraumatic stress disorder. Depress Anxiety 21: 135-139.

Liberzon I, King AP, Britton JC, Phan KL, Abelson JL, Taylor SF (2007a). Paralimbic and medial prefrontal cortical involvement in neuroendocrine responses to traumatic stimuli. Am J Psychiatry 164: 1250-1258.

Liberzon I, Martis B (2006). Neuroimaging studies of emotional responses in PTSD. Ann NY Acad Sci 1071: 87-109.

Liberzon I, Phan KL, Decker LR, Taylor SF (2003). Extended amygdala and emotional salience: a PET activation study of positive and negative affect. Neuropsychopharmacology 28: 726-733.

Liberzon I, Sripada CS (2008). The functional neuroanatomy of PTSD: a critical review. Prog Brain Res 167: 151-169.

Liberzon I, Taylor SF, Amdur R, Jung TD, Chamberlain KR, Minoshima S et al (1999). Brain activation in PTSD in response to trauma-related stimuli. Biol Psychiatry 45: 817-826.

Liberzon I, Taylor SF, Phan KL, Britton JC, Fig LM, Bueller JA et al (2007b). Altered central micro-opioid receptor binding after psychological trauma. Biol Psychiatry 61: $1030-1038$.

Liebowitz MR, Ninan PT, Schneier FR, Blanco C (2005). Integrating neurobiology and psychopathology into evidence-based treatment of social anxiety disorder. CNS Spectr 10(suppl 13): 1-11; discussion 12-13; quiz 14-15.

Lindauer RJ, Booij J, Habraken JB, Uylings HB, Olff M, Carlier IV et al (2004a). Cerebral blood flow changes during script-driven imagery in police officers with posttraumatic stress disorder. Biol Psychiatry 56: 853-861.

Lindauer RJ, Booij J, Habraken JB, van Meijel EP, Uylings HB, Olff M et al (2008). Effects of psychotherapy on regional cerebral blood flow during trauma imagery in patients with post-traumatic stress disorder: a randomized clinical trial. Psychol Med 38: 543-554.

Lindauer RJ, Vlieger EJ, Jalink M, Olff M, Carlier IV, Majoie CB et al (2004b). Smaller hippocampal volume in Dutch police officers with posttraumatic stress disorder. Biol Psychiatry 56: 356-363.

Liston C, Miller MM, Goldwater DS, Radley JJ, Rocher AB, Hof PR et al (2006). Stressinduced alterations in prefrontal cortical dendritic morphology predict selective impairments in perceptual attentional set-shifting. J Neurosci 26: 7870-7874.

Lorberbaum JP, Kose S, Johnson MR, Arana GW, Sullivan LK, Hamner MB et al (2004). Neural correlates of speech anticipatory anxiety in generalized social phobia. Neuroreport 15: 2701-2705. 
Mahmutyazicioglu K, Konuk N, Ozdemir H, Atasoy N, Atik L, Gundogdu S (2005). Evaluation of the hippocampus and the anterior cingulate gyrus by proton MR spectroscopy in patients with post-traumatic stress disorder. Diagn Interv Radiol 11: $125-129$.

Malizia AL, Cunningham VJ, Bell CJ, Liddle PF, Jones T, Nutt DJ (1998). Decreased brain $\mathrm{GABA}(\mathrm{A})$-benzodiazepine receptor binding in panic disorder: preliminary results from a quantitative PET study. Arch Gen Psychiatry 55: 715-720.

Maren S (2008). Pavlovian fear conditioning as a behavioral assay for hippocampus and amygdala function: cautions and caveats. Eur J Neurosci 28: 1661-1666.

Marschner A, Kalisch R, Vervliet B, Vansteenwegen D, Buchel C (2008). Dissociable roles for the hippocampus and the amygdala in human cued vs context fear conditioning. J Neurosci 28: 9030-9036.

Massana G, Gasto C, Junque C, Mercader JM, Gomez B, Massana J et al (2002). Reduced levels of creatine in the right medial temporal lobe region of panic disorder patients detected with (1) $\mathrm{H}$ magnetic resonance spectroscopy. Neuroimage 16: 836-842.

Massana G, Serra-Grabulosa JM, Salgado-Pineda P, Gasto C, Junque C, Massana $J$ et al (2003). Amygdalar atrophy in panic disorder patients detected by volumetric magnetic resonance imaging. Neuroimage 19: 80-90.

Mathew SJ, Coplan JD, Gorman JM (2001). Neurobiological mechanisms of social anxiety disorder. Am J Psychiatry 158: 1558-1567.

Mathew SJ, Mao X, Coplan JD, Smith EL, Sackeim HA, Gorman JM et al (2004). Dorsolateral prefrontal cortical pathology in generalized anxiety disorder: a proton magnetic resonance spectroscopic imaging study. Am J Psychiatry 161: 1119-1121.

Mayberg HS (1997). Limbic-cortical dysregulation: a proposed model of depression. J Neuropsychiatry Clin Neurosci 9: 471-481.

Mayberg HS, Liotti M, Brannan SK, McGinnis S, Mahurin RK, Jerabek PA et al (1999). Reciprocal limbic-cortical function and negative mood: converging PET findings in depression and normal sadness. Am J Psychiatry 156: 675-682.

McClure EB, Adler A, Monk CS, Cameron J, Smith S, Nelson EE et al (2007a). fMRI predictors of treatment outcome in pediatric anxiety disorders. Psychopharmacology (Berlin) 191: 97-105.

McClure EB, Monk CS, Nelson EE, Parrish JM, Adler A, Blair RJ et al (2007b). Abnormal attention modulation of fear circuit function in pediatric generalized anxiety disorder. Arch Gen Psychiatry 64: 97-106.

McEwen BS (2001). Plasticity of the hippocampus: adaptation to chronic stress and allostatic load. Ann NY Acad Sci 933: 265-277.

Menzies L, Chamberlain SR, Laird AR, Thelen SM, Sahakian BJ, Bullmore ET (2008). Integrating evidence from neuroimaging and neuropsychological studies of obsessive-compulsive disorder: the orbitofronto-striatal model revisited. Neurosci Biobehav Rev 32: 525-549.

Michelgard A, Appel L, Pissiota A, Frans O, Langstrom B, Bergstrom M et al (2007). Symptom provocation in specific phobia affects the substance $P$ neurokinin-1 receptor system. Biol Psychiatry 61: 1002-1006.

Milad MR, Orr SP, Lasko NB, Chang Y, Rauch SL, Pitman RK (2008). Presence and acquired origin of reduced recall for fear extinction in PTSD: results of a twin study. J Psychiatr Res 42: 515-520.

Milad MR, Quinn BT, Pitman RK, Orr SP, Fischl B, Rauch SL (2005). Thickness of ventromedial prefrontal cortex in humans is correlated with extinction memory. Proc Natl Acad Sci USA 102: 10706-10711.

Milad MR, Quirk GJ (2002). Neurons in medial prefrontal cortex signal memory for fear extinction. Nature 420: 70-74

Milad MR, Quirk GJ, Pitman RK, Orr SP, Fischl B, Rauch SL (2007a). A role for the human dorsal anterior cingulate cortex in fear expression. Biol Psychiatry 62: 1191-1194.

Milad MR, Wright Cl, Orr SP, Pitman RK, Quirk GJ, Rauch SL (2007b). Recall of fear extinction in humans activates the ventromedial prefrontal cortex and hippocampus in concert. Biol Psychiatry 62: 446-454.

Mitra R, Jadhav S, McEwen BS, Vyas A, Chattarji S (2005). Stress duration modulates the spatiotemporal patterns of spine formation in the basolateral amygdala. Proc Natl Acad Sci USA 102: 9371-9376.

Mohanakrishnan Menon P, Nasrallah HA, Lyons JA, Scott MF, Liberto V (2003). Single-voxel proton MR spectroscopy of right vs left hippocampi in PTSD. Psychiatry Res 123: 101-108.

Molina ME, Isoardi R, Prado MN, Bentolila S (2007). Basal cerebral glucose distribution in long-term post-traumatic stress disorder. World J Biol Psychiatry $1-9$

Monk CS, Nelson EE, McClure EB, Mogg K, Bradley BP, Leibenluft E et al (2006). Ventrolateral prefrontal cortex activation and attentional bias in response to angry faces in adolescents with generalized anxiety disorder. Am J Psychiatry 163: 1091-1097.

Monk CS, Telzer EH, Mogg K, Bradley BP, Mai X, Louro HM et al (2008). Amygdala and ventrolateral prefrontal cortex activation to masked angry faces in children and adolescents with generalized anxiety disorder. Arch Gen Psychiatry 65: 568-576.
Moores KA, Clark CR, McFarlane AC, Brown GC, Puce A, Taylor DJ (2008). Abnormal recruitment of working memory updating networks during maintenance of trauma-neutral information in post-traumatic stress disorder. Psychiatry Res 163: 156-170.

Morey RA, Dolcos F, Petty CM, Cooper DA, Hayes JP, Labar KS et al (2009). The role of trauma-related distractors on neural systems for working memory and emotion processing in posttraumatic stress disorder. J Psychiatr Res 43: 809-817.

Morgan MA, Romanski LM, LeDoux JE (1993). Extinction of emotional learning: contribution of medial prefrontal cortex. Neurosci Lett 163: 109-113.

Morris JS, Buchel C, Dolan RJ (2001). Parallel neural responses in amygdala subregions and sensory cortex during implicit fear conditioning. Neuroimage 13: 1044-1052.

Morris JS, Dolan RJ (2004). Dissociable amygdala and orbitofrontal responses during reversal fear conditioning. Neuroimage 22: 372-380.

Morris JS, Frith CD, Perrett DI, Rowland D, Young AW, Calder AJ et al (1996). A differential neural response in the human amygdala to fearful and happy facial expressions. Nature 383: 812-815.

Morris JS, Ohman A, Dolan RJ (1998). Conscious and unconscious emotional learning in the human amygdala. Nature 393: 467-470.

Nader K, Hardt O (2009). A single standard for memory: the case for reconsolidation. Nat Rev Neurosci 10: 224-234.

Nash JR, Sargent PA, Rabiner EA, Hood SD, Argyropoulos SV, Potokar JP et al (2008). Serotonin 5-HT1A receptor binding in people with panic disorder: positron emission tomography study. Br J Psychiatry 193: 229-234.

Neumeister A, Bain E, Nugent AC, Carson RE, Bonne O, Luckenbaugh DA et al (2004). Reduced serotonin type 1A receptor binding in panic disorder. J Neurosci 24: 589-591.

Nitschke JB, Sarinopoulos I, Oathes DJ, Johnstone T, Whalen PJ, Davidson RJ et al (2009). Anticipatory activation in the amygdala and anterior cingulate in generalized anxiety disorder and prediction of treatment response. Am J Psychiatry 166: 302-310.

Nordahl TE, Semple WE, Gross M, Mellman TA, Stein MB, Goyer P et al (1990). Cerebral glucose metabolic differences in patients with panic disorder. Neuropsychopharmacology 3: 261-272.

Nordahl TE, Stein MB, Benkelfat C, Semple WE, Andreason P, Zametkin A et al (1998). Regional cerebral metabolic asymmetries replicated in an independent group of patients with panic disorders. Biol Psychiatry 44: 998-1006.

Ochsner KN, Bunge SA, Gross JJ, Gabrieli JD (2002). Rethinking feelings: an FMRI study of the cognitive regulation of emotion. J Cogn Neurosci 14: 1215-1229.

Olsson A, Nearing KI, Phelps EA (2007). Learning fears by observing others: the neural systems of social fear transmission. Soc Cogn Affect Neurosci 2: 3-11.

Orr SP, Metzger LJ, Lasko NB, Macklin ML, Peri T, Pitman RK (2000). De novo conditioning in trauma-exposed individuals with and without posttraumatic stress disorder. J Abnorm Psychol 109: 290-298.

Osuch EA, Benson B, Geraci M, Podell D, Herscovitch P, McCann UD et al (2001). Regional cerebral blood flow correlated with flashback intensity in patients with posttraumatic stress disorder. Biol Psychiatry 50: 246-253.

Osuch EA, Willis MW, Bluhm R, Ursano RJ, Drevets WC (2008). Neurophysiological responses to traumatic reminders in the acute aftermath of serious motor vehicle collisions using [15O]-H2O positron emission tomography. Biol Psychiatry 64: 327-335.

Pannu Hayes J, Labar KS, Petty CM, McCarthy G, Morey RA (2009). Alterations in the neural circuitry for emotion and attention associated with posttraumatic stress symptomatology. Psychiatry Res 172: 7-15.

Paquette V, Levesque J, Mensour B, Leroux JM, Beaudoin G, Bourgouin P et al (2003). 'Change the mind and you change the brain': effects of cognitivebehavioral therapy on the neural correlates of spider phobia. Neuroimage 18: 401-409.

Paradiso S, Johnson DL, Andreasen NC, O'Leary DS, Watkins GL, Ponto LL et al (1999). Cerebral blood flow changes associated with attribution of emotional valence to pleasant, unpleasant, and neutral visual stimuli in a PET study of normal subjects. Am J Psychiatry 156: 1618-1629.

Pare D, Quirk GJ, Ledoux JE (2004). New vistas on amygdala networks in conditioned fear. J Neurophysiol 92: 1-9.

Paulus MP, Feinstein JS, Castillo G, Simmons AN, Stein MB (2005). Dosedependent decrease of activation in bilateral amygdala and insula by lorazepam during emotion processing. Arch Gen Psychiatry 62: 282-288.

Paulus MP, Stein MB (2006). An insular view of anxiety. Biol Psychiatry 60: 383-387.

Pederson CL, Maurer SH, Kaminski PL, Zander KA, Peters CM, Stokes-Crowe LA et al (2004). Hippocampal volume and memory performance in a communitybased sample of women with posttraumatic stress disorder secondary to child abuse. J Trauma Stress 17: 37-40.

Perani D, Garibotto V, Gorini A, Moresco RM, Henin M, Panzacchi A et al (2008). In vivo PET study of $5 H T(2 A)$ serotonin and $D(2)$ dopamine dysfunction in drugnaive obsessive-compulsive disorder. Neuroimage 42: 306-314. 
Peres JF, Newberg AB, Mercante JP, Simao M, Albuquerque VE, Peres MJ et al (2007). Cerebral blood flow changes during retrieval of traumatic memories before and after psychotherapy: a SPECT study. Psychol Med 37: 1481-1491.

Peri T, Ben-Shakhar G, Orr SP, Shalev AY (2000). Psychophysiologic assessment of aversive conditioning in posttraumatic stress disorder. Biol Psychiatry 47: 512-519.

Phan KL, Britton JC, Taylor SF, Fig LM, Liberzon I (2006a). Corticolimbic blood flow during nontraumatic emotional processing in posttraumatic stress disorder. Arch Gen Psychiatry 63: 184-192.

Phan KL, Fitzgerald DA, Cortese BM, Seraji-Bozorgzad N, Tancer ME, Moore GJ (2005). Anterior cingulate neurochemistry in social anxiety disorder: $1 \mathrm{H}-\mathrm{MRS}$ at 4 Tesla. Neuroreport 16: 183-186.

Phan KL, Fitzgerald DA, Gao K, Moore GJ, Tancer ME, Posse S (2004a). Real-time $\mathrm{fMRI}$ of cortico-limbic brain activity during emotional processing. Neuroreport 15: $527-532$.

Phan KL, Fitzgerald DA, Nathan PJ, Tancer ME (2006b). Association between amygdala hyperactivity to harsh faces and severity of social anxiety in generalized social phobia. Biol Psychiatry 59: 424-429.

Phan KL, Liberzon I, Welsh RC, Britton JC, Taylor SF (2003a). Habituation of rostral anterior cingulate cortex to repeated emotionally salient pictures. Neuropsychopharmacology 28: 1344-1350.

Phan KL, Taylor SF, Welsh RC, Decker LR, Noll DC, Nichols TE et al (2003b). Activation of the medial prefrontal cortex and extended amygdala by individual ratings of emotional arousal: a fMRI study. Biol Psychiatry 53: 211-215.

Phan KL, Wager T, Taylor SF, Liberzon I (2002). Functional neuroanatomy of emotion: a meta-analysis of emotion activation studies in PET and $\mathrm{FMRI}$ Neuroimage 16: 331-348.

Phan KL, Wager TD, Taylor SF, Liberzon I (2004b). Functional neuroimaging studies of human emotions. CNS Spectr 9: 258-266.

Phelps EA, Delgado MR, Nearing Kl, LeDoux JE (2004). Extinction learning in humans: role of the amygdala and vmPFC. Neuron 43: 897-905.

Phelps EA, O'Connor KJ, Gatenby JC, Gore JC, Grillon C, Davis M (2001). Activation of the left amygdala to a cognitive representation of fear. Nat Neurosci 4: 437-441.

Phillips ML, Williams LM, Heining M, Herba CM, Russell T, Andrew C et al (2004). Differential neural responses to overt and covert presentations of facial expressions of fear and disgust. Neuroimage 21: 1484-1496.

Phillips ML, Young AW, Senior C, Brammer M, Andrew C, Calder AJ et al (1997). A specific neural substrate for perceiving facial expressions of disgust. Nature 389: 495-498

Pillay SS, Gruber SA, Rogowska J, Simpson N, Yurgelun-Todd DA (2006). fMRI of fearful facial affect recognition in panic disorder: the cingulate gyrus-amygdala connection. J Affect Disord 94: 173-181.

Pillay SS, Rogowska J, Gruber SA, Simpson N, Yurgelun-Todd DA (2007). Recognition of happy facial affect in panic disorder: an fMRl study. $J$ Anxiety Disord 21: 381-393.

Pine DS, Fyer A, Grun J, Phelps EA, Szeszko PR, Koda V et al (2001). Methods for developmental studies of fear conditioning circuitry. Biol Psychiatry 50: 225-228.

Pissiota A, Frans O, Fernandez M, von Knorring L, Fischer H, Fredrikson M (2002). Neurofunctional correlates of posttraumatic stress disorder: a PET symptom provocation study. Eur Arch Psychiatry Clin Neurosci 252: 68-75.

Pissiota A, Frans O, Michelgard A, Appel L, Langstrom B, Flaten MA et al (2003). Amygdala and anterior cingulate cortex activation during affective startle modulation: a PET study of fear. Eur J Neurosci 18: 1325-1331.

Plotsky PM, Meaney MJ (1993). Early, postnatal experience alters hypothalamic corticotropin-releasing factor (CRF) mRNA, median eminence CRF content and stress-induced release in adult rats. Brain Res Mol Brain Res 18: 195-200.

Pohl J, Olmstead MC, Wynne-Edwards KE, Harkness K, Menard JL (2007). Repeated exposure to stress across the childhood-adolescent period alters rats' anxiety- and depression-like behaviors in adulthood: the importance of stressor type and gender. Behav Neurosci 121: 462-474.

Protopopescu X, Pan H, Tuescher O, Cloitre M, Goldstein M, Engelien A et al (2006). Increased brainstem volume in panic disorder: a voxel-based morphometric study. Neuroreport 17: 361-363.

Protopopescu X, Pan H, Tuescher O, Cloitre M, Goldstein M, Engelien W et al (2005). Differential time courses and specificity of amygdala activity in posttraumatic stress disorder subjects and normal control subjects. Biol Psychiatry 57: 464-473.

Quadflieg S, Mohr A, Mentzel HJ, Miltner WH, Straube T (2008). Modulation of the neural network involved in the processing of anger prosody: the role of taskrelevance and social phobia. Biol Psychol 78: 129-137.

Quirk GJ, Garcia R, Gonzalez-Lima F (2006). Prefrontal mechanisms in extinction of conditioned fear. Biol Psychiatry 60: 337-343.

Quirk GJ, Likhtik E, Pelletier JG, Pare D (2003). Stimulation of medial prefrontal cortex decreases the responsiveness of central amygdala output neurons. J Neurosci 23: 8800-8807
Quirk GJ, Mueller D (2008). Neural mechanisms of extinction learning and retrieval. Neuropsychopharmacology 33: 56-72.

Quirk GJ, Russo GK, Barron JL, Lebron K (2000). The role of ventromedial prefrontal cortex in the recovery of extinguished fear. J Neurosci 20: 6225-6231.

Radley JJ, Sisti HM, Hao J, Rocher AB, McCall T, Hof PR et al (2004). Chronic behavioral stress induces apical dendritic reorganization in pyramidal neurons of the medial prefrontal cortex. Neuroscience 125: 1-6.

Rauch S, Whalen P, Dougherty D, Jenike M (1998a). Neurobiological models of obsessive compulsive disorders. In: Jenike M, Baer L, Minichiello W (eds) Obsessive-Compulsive Disorders: Practical Management. Mosby, Baston, MA. pp 222-253.

Rauch SL, Jenike MA, Alpert NM, Baer L, Breiter HC, Savage CR et al (1994). Regional cerebral blood flow measured during symptom provocation in obsessive-compulsive disorder using oxygen 15-labeled carbon dioxide and positron emission tomography. Arch Gen Psychiatry 51: 62-70.

Rauch SL, Savage CR, Alpert NM, Dougherty D, Kendrick A, Curran Tet al (1997). Probing striatal function in obsessive-compulsive disorder: a PET study of implicit sequence learning. J Neuropsychiatry Clin Neurosci 9: 568-573.

Rauch SL, Shin LM, Phelps EA (2006). Neurocircuitry models of posttraumatic stress disorder and extinction: human neuroimaging research - past, present, and future. Biol Psychiatry 60: 376-382.

Rauch SL, Shin LM, Segal E, Pitman RK, Carson MA, McMullin K et al (2003). Selectively reduced regional cortical volumes in post-traumatic stress disorder. Neuroreport 14: 913-916.

Rauch SL, Shin LM, Whalen PJ, Pitman RK (1998b). Neuroimaging and the neuroanatomy of PTSD. CNS Spectrums 3(Suppl. 2): 30-41.

Rauch SL, Whalen PJ, Shin LM, Mclnerney SC, Macklin ML, Lasko NB et al (2000). Exaggerated amygdala response to masked facial stimuli in posttraumatic stress disorder: a functional MRI study. Biol Psychiatry 47: 769-776.

Rauch SL, Wright Cl, Martis B, Busa E, McMullin KG, Shin LM et al (2004). A magnetic resonance imaging study of cortical thickness in animal phobia. Biol Psychiatry 55: 946-952.

Reiger D, Burke J, Burke K (1990). Comorbidity of affective and anxiety disorders in the NIHM Epidemiologic Catchment Area program. In: Maser J, Cloninger R (eds). Comorbidity of Mood and Anxiety Disorders. American Psychiatric Press, Washington, DC

Reiman EM, Lane RD, Ahern GL, Schwartz GE, Davidson RJ, Friston KJ et al (1997). Neuroanatomical correlates of externally and internally generated human emotion. Am J Psychiatry 154: 918-925.

Reimold M, Smolka MN, Zimmer A, Batra A, Knobel A, Solbach C et al (2007). Reduced availability of serotonin transporters in obsessive-compulsive disorder correlates with symptom severity - a [11C]DASB PET study. J Neural Transm 114: 1603-1609.

Remijnse PL, Nielen MM, van Balkom AJ, Cath DC, van Oppen P, Uylings HB et al (2006). Reduced orbitofrontal-striatal activity on a reversal learning task in obsessive-compulsive disorder. Arch Gen Psychiatry 63: 1225-1236.

Robinson D, Wu H, Munne RA, Ashtari M, Alvir JM, Lerner G et al (1995). Reduced caudate nucleus volume in obsessive-compulsive disorder. Arch Gen Psychiatry 52: 393-398.

Root JC, Tuescher O, Cunningham-Bussel A, Pan H, Epstein J, Altemus $\mathrm{M}$ et al (2009). Frontolimbic function and cortisol reactivity in response to emotional stimuli. Neuroreport 20: 429-434.

Rosenberg DR, Keshavan MS, O'Hearn KM, Dick EL, Bagwell WW, Seymour AB et al (1997). Frontostriatal measurement in treatment-naive children with obsessive-compulsive disorder. Arch Gen Psychiatry 54: 824-830.

Sabatini E, Penna SD, Franciotti R, Ferretti A, Zoccolotti P, Rossini PM et al (2009). Brain structures activated by overt and covert emotional visual stimuli. Brain Res Bull 79: 258-264.

Sachinvala N, Kling A, Suffin S, Lake R, Cohen M (2000). Increased regional cerebral perfusion by $99 \mathrm{mTc}$ hexamethyl propylene amine oxime single photon emission computed tomography in post-traumatic stress disorder. Mil Med 165 473-479.

Sakai Y, Kumano H, Nishikawa M, Sakano Y, Kaiya H, Imabayashi E et al (2005). Cerebral glucose metabolism associated with a fear network in panic disorder. Neuroreport 16: 927-931.

Sakai Y, Kumano H, Nishikawa M, Sakano Y, Kaiya H, Imabayashi E et al (2006). Changes in cerebral glucose utilization in patients with panic disorder treated with cognitive-behavioral therapy. Neuroimage 33: 218-226.

Sananes CB, Davis M (1992). N-methyl-D-aspartate lesions of the lateral and basolateral nuclei of the amygdala block fear-potentiated startle and shock sensitization of startle. Behav Neurosci 106: 72-80.

Sareen J, Campbell DW, Leslie WD, Malisza KL, Stein MB, Paulus MP et al (2007). Striatal function in generalized social phobia: a functional magnetic resonance imaging study. Biol Psychiatry 61: 396-404. 
Schienle A, Schafer A, Hermann A, Rohrmann S, Vaitl D (2007). Symptom provocation and reduction in patients suffering from spider phobia: an fMRI study on exposure therapy. Eur Arch Psychiatry Clin Neurosci 257: 486-493.

Schienle A, Schafer A, Walter B, Stark R, Vaitl D (2005). Brain activation of spider phobics towards disorder-relevant, generally disgust- and fear-inducing pictures. Neurosci Lett 388: 1-6.

Schneider F, Weiss U, Kessler C, Muller-Gartner HW, Posse S, Salloum JB et al (1999). Subcortical correlates of differential classical conditioning of aversive emotional reactions in social phobia. Biol Psychiatry 45: 863-871.

Schneier FR, Abi-Dargham A, Martinez D, Slifstein M, Hwang DR, Liebowitz MR et al (2009). Dopamine transporters, $D(2)$ receptors, and dopamine release in generalized social anxiety disorder. Depress Anxiety 26: 411-418.

Schneier FR, Liebowitz MR, Abi-Dargham A, Zea-Ponce Y, Lin SH, Laruelle M (2000). Low dopamine $D(2)$ receptor binding potential in social phobia. Am J Psychiatry 157: 457-459.

Schuff N, Neylan TC, Fox-Bosetti S, Lenoci M, Samuelson KW, Studholme C et al (2008). Abnormal $N$-acetylaspartate in hippocampus and anterior cingulate in posttraumatic stress disorder. Psychiatry Res 162: 147-157.

Schuff N, Neylan TC, Lenoci MA, Du AT, Weiss DS, Marmar CR et al (2001). Decreased hippocampal $N$-acetylaspartate in the absence of atrophy in posttraumatic stress disorder. Biol Psychiatry 50: 952-959.

Schunck T, Erb G, Mathis A, Gilles C, Namer IJ, Hode Y et al (2006). Functional magnetic resonance imaging characterization of CCK-4-induced panic attack and subsequent anticipatory anxiety. Neuroimage 31: 1197-1208.

Schwartz CE, Snidman N, Kagan J (1999). Adolescent social anxiety as an outcome of inhibited temperament in childhood. J Am Acad Child Adolesc Psychiatry 38: 1008-1015.

Schwartz CE, Wright Cl, Shin LM, Kagan J, Rauch SL (2003). Inhibited and uninhibited infants 'grown up': adult amygdalar response to novelty. Science 300: 1952-1953.

Seedat S, Warwick J, van Heerden B, Hugo C, Zungu-Dirwayi N, Van Kradenburg J et al (2004). Single photon emission computed tomography in posttraumatic stress disorder before and after treatment with a selective serotonin reuptake inhibitor. J Affect Disord 80: 45-53.

Semple WE, Goyer PF, McCormick R, Donovan B, Muzic Jr RF, Rugle L et al (2000). Higher brain blood flow at amygdala and lower frontal cortex blood flow in PTSD patients with comorbid cocaine and alcohol abuse compared with normals. Psychiatry 63: 65-74.

Servan-Schreiber D, Perlstein WM, Cohen JD, Mintun M (1998). Selective pharmacological activation of limbic structures in human volunteers: a positron emission tomography study. J Neuropsychiatry Clin Neurosci 10: 148-159.

Shin LM, Bush G, Whalen PJ, Handwerger K, Cannistraro PA, Wright $\mathrm{Cl}$ et al (2007). Dorsal anterior cingulate function in posttraumatic stress disorder. $\checkmark$ Trauma Stress 20: 701-712.

Shin LM, Kosslyn SM, McNally RJ, Alpert NM, Thompson WL, Rauch SL et al (1997). Visual imagery and perception in posttraumatic stress disorder. A positron emission tomographic investigation. Arch Gen Psychiatry 54: 233-241.

Shin LM, Lasko NB, Macklin ML, Karpf RD, Milad MR, Orr SP et al. Resting metabolic activity in cingulate cortex and vulnerability to posttraumatic stress disorder. Arch Gen Psychiatry (in press).

Shin LM, McNally RJ, Kosslyn SM, Thompson WL, Rauch SL, Alpert NM et al (1999). Regional cerebral blood flow during script-driven imagery in childhood sexual abuse-related PTSD: a PET investigation. Am J Psychiatry 156: 575-584.

Shin LM, Orr SP, Carson MA, Rauch SL, Macklin ML, Lasko NB et al (2004a). Regional cerebral blood flow in amygdala and medial prefrontal cortex during traumatic imagery in male and female Vietnam veterans with PTSD. Arch Gen Psychiatry 61: 168-176.

Shin LM, Shin PS, Heckers S, Krangel TS, Macklin ML, Orr SP et al (2004b). Hippocampal function in posttraumatic stress disorder. Hippocampus 14: 292-300.

Shin LM, Whalen PJ, Pitman RK, Bush G, Macklin ML, Lasko NB et al (2001). An fMRI study of anterior cingulate function in posttraumatic stress disorder. Biol Psychiatry 50: 932-942.

Shin LM, Wright CI, Cannistraro PA, Wedig MM, McMullin K, Martis B et al (2005). A functional magnetic resonance imaging study of amygdala and medial prefrontal cortex responses to overtly presented fearful faces in posttraumatic stress disorder. Arch Gen Psychiatry 62: 273-281.

Simmons A, Strigo I, Matthews SC, Paulus MP, Stein MB (2006). Anticipation of aversive visual stimuli is associated with increased insula activation in anxietyprone subjects. Biol Psychiatry 60: 402-409.

Simmons AN, Paulus MP, Thorp SR, Matthews SC, Norman SB, Stein MB (2008). Functional activation and neural networks in women with posttraumatic stress disorder related to intimate partner violence. Biol Psychiatry 64: 681-690.

Smith ME (2005). Bilateral hippocampal volume reduction in adults with posttraumatic stress disorder: a meta-analysis of structural MRI studies. Hippocampus 15: 798-807.
Smoller JW, Pollack MH, Wassertheil-Smoller S, Jackson RD, Oberman A, Wong ND et al (2007). Panic attacks and risk of incident cardiovascular events among postmenopausal women in the Women's Health Initiative Observational Study. Arch Gen Psychiatry 64: 1153-1160.

Somerville LH, Kim H, Johnstone T, Alexander AL, Whalen PJ (2004). Human amygdala responses during presentation of happy and neutral faces: correlations with state anxiety. Biol Psychiatry 55: 897-903

Sprengelmeyer R, Rausch M, Eysel UT, Przuntek H (1998). Neural structures associated with recognition of facial expressions of basic emotions. Proc Biol Sci 265: 1927-1931.

Stark R, Wolf OT, Tabbert K, Kagerer S, Zimmermann M, Kirsch P et al (2006). Influence of the stress hormone cortisol on fear conditioning in humans: evidence for sex differences in the response of the prefrontal cortex. Neuroimage 32: 1290-1298.

Stein DJ, Westenberg HG, Liebowitz MR (2002a). Social anxiety disorder and generalized anxiety disorder: serotonergic and dopaminergic neurocircuitry. J Clin Psychiatry 63(Suppl 6): 12-19.

Stein MB (1998). Neurobiological perspectives on social phobia: from affiliation to zoology. Biol Psychiatry 44: 1277-1285

Stein MB, Goldin PR, Sareen J, Zorrilla LT, Brown GG (2002b). Increased amygdala activation to angry and contemptuous faces in generalized social phobia. Arch Gen Psychiatry 59: 1027-1034.

Stein MB, Koverola C, Hanna C, Torchia MG, McClarty B (1997). Hippocampal volume in women victimized by childhood sexual abuse. Psychol Med 27: 951-959.

Stein MB, Simmons AN, Feinstein JS, Paulus MP (2007). Increased amygdala and insula activation during emotion processing in anxiety-prone subjects. Am J Psychiatry 164: 318-327.

Straube T, Glauer M, Dilger S, Mentzel HJ, Miltner WH (2006a). Effects of cognitivebehavioral therapy on brain activation in specific phobia. Neuroimage 29: 125-135.

Straube T, Kolassa IT, Glauer M, Mentzel HJ, Miltner WH (2004a). Effect of task conditions on brain responses to threatening faces in social phobics: an event-related functional magnetic resonance imaging study. Biol Psychiatry 56: 921-930.

Straube T, Mentzel HJ, Glauer M, Miltner WH (2004b). Brain activation to phobiarelated words in phobic subjects. Neurosci Lett 372: 204-208.

Straube T, Mentzel HJ, Miltner WH (2005). Common and distinct brain activation to threat and safety signals in social phobia. Neuropsychobiology 52: 163-168.

Straube T, Mentzel HJ, Miltner WH (2006b). Neural mechanisms of automatic and direct processing of phobogenic stimuli in specific phobia. Biol Psychiatry 59: $162-170$

Straube T, Mentzel HJ, Miltner WH (2007). Waiting for spiders: brain activation during anticipatory anxiety in spider phobics. Neuroimage 37: 1427-1436.

Tabbert K, Stark R, Kirsch P, Vaitl D (2006). Dissociation of neural responses and skin conductance reactions during fear conditioning with and without awareness of stimulus contingencies. Neuroimage 32: 761-770.

Taylor SF, Liberzon I, Fig LM, Decker LR, Minoshima S, Koeppe RA (1998). The effect of emotional content on visual recognition memory: a PET activation study. Neuroimage 8: 188-197.

Teasdale JD, Howard RJ, Cox SG, Ha Y, Brammer MJ, Williams SC et al (1999). Functional MRI study of the cognitive generation of affect. Am J Psychiatry 156: 209-215.

Thomaes K, Dorrepaal E, Draijer NP, de Ruiter MB, Elzinga BM, van Balkom AJ et al (2009). Increased activation of the left hippocampus region in Complex PTSD during encoding and recognition of emotional words: a pilot study. Psychiatry Res 171: 44-53.

Tiihonen J, Kuikka J, Bergstrom K, Lepola U, Koponen H, Leinonen E (1997). Dopamine reuptake site densities in patients with social phobia. Am J Psychiatry 154: 239-242.

Tillfors M, Furmark T, Marteinsdottir I, Fischer H, Pissiota A, Langstrom B et al (2001). Cerebral blood flow in subjects with social phobia during stressful speaking tasks: a PET study. Am J Psychiatry 158: 1220-1226.

Tillfors M, Furmark T, Marteinsdottir I, Fredrikson M (2002). Cerebral blood flow during anticipation of public speaking in social phobia: a PET study. Biol Psychiatry 52: 1113-1119.

Uchida RR, Del-Ben CM, Busatto GF, Duran FL, Guimaraes FS, Crippa JA et al (2008). Regional gray matter abnormalities in panic disorder: a voxel-based morphometry study. Psychiatry Res 163: 21-29.

Urry HL, van Reekum CM, Johnstone T, Kalin NH, Thurow ME, Schaefer HS et al (2006). Amygdala and ventromedial prefrontal cortex are inversely coupled during regulation of negative affect and predict the diurnal pattern of cortisol secretion among older adults. J Neurosci 26: 4415-4425. 
Valente Jr AA, Miguel EC, Castro CC, Amaro Jr E, Duran FL, Buchpiguel CA et al (2005). Regional gray matter abnormalities in obsessive-compulsive disorder: a voxel-based morphometry study. Biol Psychiatry 58: 479-487.

Van Ameringen M, Mancini C, Szechtman H, Nahmias C, Oakman JM, Hall GB et al (2004). A PET provocation study of generalized social phobia. Psychiatry Res 132: $13-18$.

van den Heuvel OA, Veltman DJ, Groenewegen HJ, Cath DC, van Balkom AJ, van Hartskamp $\mathrm{J}$ et al (2005a). Frontal-striatal dysfunction during planning in obsessive-compulsive disorder. Arch Gen Psychiatry 62: 301-309.

van den Heuvel OA, Veltman DJ, Groenewegen HJ, Dolan RJ, Cath DC, Boellaard $R$ et al (2004). Amygdala activity in obsessive-compulsive disorder with contamination fear: a study with oxygen-15 water positron emission tomography. Psychiatry Res 132: 225-237.

van den Heuvel OA, Veltman DJ, Groenewegen HJ, Witter MP, Merkelbach J, Cath DC et al (2005b). Disorder-specific neuroanatomical correlates of attentional bias in obsessive-compulsive disorder, panic disorder, and hypochondriasis. Arch Gen Psychiatry 62: 922-933.

Van Laere K, Nuttin B, Gabriels L, Dupont P, Rasmussen S, Greenberg BD et al (2006). Metabolic imaging of anterior capsular stimulation in refractory obsessivecompulsive disorder: a key role for the subgenual anterior cingulate and ventral striatum. J Nucl Med 47: 740-747.

Veit R, Flor H, Erb M, Hermann C, Lotze M, Grodd W et al (2002). Brain circuits involved in emotional learning in antisocial behavior and social phobia in humans. Neurosci Lett 328: 233-236.

Veltman DJ, Tuinebreijer WE, Winkelman D, Lammertsma AA, Witter MP, Dolan RJ et al (2004). Neurophysiological correlates of habituation during exposure in spider phobia. Psychiatry Res 132: 149-158.

Vermetten E, Schmahl C, Southwick SM, Bremner JD (2007). Positron tomographic emission study of olfactory induced emotional recall in veterans with and without combat-related posttraumatic stress disorder. Psychopharmacol Bull 40: 8-30.

Vermetten E, Vythilingam M, Southwick SM, Charney DS, Bremner JD (2003). Long-term treatment with paroxetine increases verbal declarative memory and hippocampal volume in posttraumatic stress disorder. Biol Psychiatry 54: 693-702.

Villarreal G, Hamilton DA, Petropoulos H, Driscoll I, Rowland LM, Griego JA et al (2002a). Reduced hippocampal volume and total white matter volume in posttraumatic stress disorder. Biol Psychiatry 52: 119-125.

Villarreal G, Petropoulos H, Hamilton DA, Rowland LM, Horan WP, Griego JA et al (2002b). Proton magnetic resonance spectroscopy of the hippocampus and occipital white matter in PTSD: preliminary results. Can J Psychiatry 47: 666-670.

Vuilleumier P, Pourtois G (2007). Distributed and interactive brain mechanisms during emotion face perception: evidence from functional neuroimaging. Neuropsychologia 45: 174-194.

Vyas A, Jadhav S, Chattarji S (2006). Prolonged behavioral stress enhances synaptic connectivity in the basolateral amygdala. Neuroscience 143: 387-393.

Wendt J, Lotze M, Weike Al, Hosten N, Hamm AO (2008). Brain activation and defensive response mobilization during sustained exposure to phobia-related and other affective pictures in spider phobia. Psychophysiology 45: 205-215.

Werner NS, Meindl T, Engel RR, Rosner R, Riedel M, Reiser M et al (2009). Hippocampal function during associative learning in patients with posttraumatic stress disorder. J Psychiatr Res 43: 309-318.

Wessa M, Flor H (2007). Failure of extinction of fear responses in posttraumatic stress disorder: evidence from second-order conditioning. Am J Psychiatry 164: 1684-1692.

Whalen PJ, Johnstone T, Somerville LH, Nitschke JB, Polis S, Alexander AL et al (2008). A functional magnetic resonance imaging predictor of treatment response to venlafaxine in generalized anxiety disorder. Biol Psychiatry 63: 858-863.
Whalen PJ, Kagan J, Cook RG, Davis FC, Kim H, Polis S et al (2004). Human amygdala responsivity to masked fearful eye whites. Science 306: 2061.

Whalen PJ, Rauch SL, Etcoff NL, Mclnerney SC, Lee MB, Jenike MA (1998). Masked presentations of emotional facial expressions modulate amygdala activity without explicit knowledge. J Neurosci 18: 411-418.

Whalen PJ, Shin LM, Mcinerney SC, Fischer H, Wright Cl, Rauch SL (2001). A functional MRI study of human amygdala responses to facial expressions of fear vs anger. Emotion 1: 70-83.

Whalley MG, Rugg MD, Smith AP, Dolan RJ, Brewin CR (2009). Incidental retrieval of emotional contexts in post-traumatic stress disorder and depression: An fMRI study. Brain Cogn 69: 98-107.

Wignall EL, Dickson JM, Vaughan P, Farrow TF, Wilkinson ID, Hunter MD et al (2004). Smaller hippocampal volume in patients with recent-onset posttraumatic stress disorder. Biol Psychiatry 56: 832-836.

Wik G, Fredrikson M, Fischer H (1996). Cerebral correlates of anticipated fear: a PET study of specific phobia. Int J Neurosci 87: 267-276.

Wik G, Fredrikson M, Fischer H (1997). Evidence of altered cerebral blood-flow relationships in acute phobia. Int J Neurosci 91: 253-263.

Williams LM, Kemp AH, Felmingham K, Barton M, Olivieri G, Peduto A et al (2006). Trauma modulates amygdala and medial prefrontal responses to consciously attended fear. Neuroimage 29: 347-357.

Winter H, Irle E (2004). Hippocampal volume in adult burn patients with and without posttraumatic stress disorder. Am J Psychiatry 161: 2194-2200.

Woodward SH, Kaloupek DG, Streeter CC, Martinez C, Schaer M, Eliez S (2006). Decreased anterior cingulate volume in combat-related PTSD. Biol Psychiatry 59: $582-587$

Woon FL, Hedges DW (2008). Hippocampal and amygdala volumes in children and adults with childhood maltreatment-related posttraumatic stress disorder: a meta-analysis. Hippocampus 18: 729-736.

Wright Cl, Martis B, McMullin K, Shin LM, Rauch SL (2003). Amygdala and insular responses to emotionally valenced human faces in small animal specific phobia. Biol Psychiatry 54: 1067-1076.

Yamasue H, Kasai K, Iwanami A, Ohtani T, Yamada H, Abe O et al (2003). Voxelbased analysis of MRI reveals anterior cingulate gray-matter volume reduction in posttraumatic stress disorder due to terrorism. Proc Natl Acad Sci USA 100: 9039-9043.

Yang P, Wu MT, Hsu CC, Ker JH (2004). Evidence of early neurobiological alternations in adolescents with posttraumatic stress disorder: a functional MRI study. Neurosci Lett 370: 13-18.

Yehuda R (2006). Advances in understanding neuroendocrine alterations in PTSD and their therapeutic implications. Ann NY Acad Sci 1071: 137-166.

Yehuda R, Giller EL, Southwick SM, Lowy MT, Mason JW (1991). Hypothalamicpituitary-adrenal dysfunction in posttraumatic stress disorder. Biol Psychiatry 30: $1031-1048$.

Yoon KL, Fitzgerald DA, Angstadt M, McCarron RA, Phan KL (2007). Amygdala reactivity to emotional faces at high and low intensity in generalized social phobia: a 4-Tesla functional MRI study. Psychiatry Res 154: 93-98.

Zald DH, Lee JT, Fluegel KW, Pardo JV (1998). Aversive gustatory stimulation activates limbic circuits in humans. Brain 121(Part 6): 1143-1154.

Zald DH, Pardo JV (1997). Emotion, olfaction, and the human amygdala: amygdala activation during aversive olfactory stimulation. Proc Natl Acad Sci USA 94: 4119-4124.

Zysset S, Huber O, Ferstl E, von Cramon DY (2002). The anterior frontomedian cortex and evaluative judgment: an fMRI study. Neuroimage 15: 983-991. 


\section{APPENDIX}

\section{Introduction}

I. Fear neurocircuitry in healthy humans

A. Pavlovian fear conditioning and extinction
(i) Fear conditioning
(ii) Extinction

B. Fear states and responses to challenge
(i) Pharmacological challenge
(ii) Emotional stimuli
(iii) Emotional facial expressions

C. Summary

II. Stress

III. Anxiety disorders

A. Posttraumatic stress disorder
(i) Amygdala
(ii) Medial prefrontal cortex
(iii) Hippocampus
(iv) Insular cortex
(v) Summary

B. Panic disorder
(i) Amygdala
(ii) Medial prefrontal cortex
(iii) Hippocampus
(iv) Insular cortex
(v) Brainstem
(vi) Summary
C. Social phobia
(i) Amygdala
(ii) Medial prefrontal cortex
(iii) Insular cortex
(iv) Striatum
(v) Summary

D. Specific phobia
(i) Amygdala
(ii) Medial prefrontal cortex
(iii) Insular cortex
(iv) Summary

E. Obsessive-compulsive disorder

F. Generalized anxiety disorder
(i) Amygdala
(ii) Medial prefrontal cortex
(iii) Summary

G. Summary

IV. Future research directions 